\title{
Review Article \\ Recent Advances in Heterogeneous Photocatalytic Decolorization of Synthetic Dyes
}

\author{
Nurhidayatullaili Muhd Julkapli, Samira Bagheri, and Sharifah Bee Abd Hamid \\ Nanotechnology \& Catalysis Research Centre (NANOCAT), IPS Building, University Malaya, 50603 Kuala Lumpur, Malaysia \\ Correspondence should be addressed to Samira Bagheri; samira_bagheri@um.edu.my
}

Received 19 February 2014; Revised 10 April 2014; Accepted 14 April 2014; Published 25 June 2014

Academic Editor: Baibiao Huang

Copyright ( 2014 Nurhidayatullaili Muhd Julkapli et al. This is an open access article distributed under the Creative Commons Attribution License, which permits unrestricted use, distribution, and reproduction in any medium, provided the original work is properly cited.

\begin{abstract}
During the process and operation of the dyes, the wastes produced were commonly found to contain organic and inorganic impurities leading to risks in the ecosystem and biodiversity with the resultant impact on the environment. Improper effluent disposal in aqueous ecosystems leads to reduction of sunlight penetration which in turn diminishes photosynthetic activity, resulting in acute toxic effects on the aquatic flora/fauna and dissolved oxygen concentration. Recently, photodegradation of various synthetic dyes has been studied in terms of their absorbance and the reduction of oxygen content by changes in the concentration of the dye. The advantages that make photocatalytic techniques superior to traditional methods are the ability to remove contaminates in the range of $\mathrm{ppb}$, no generation of polycyclic compounds, higher speed, and lower cost. Semiconductor metal oxides, typically $\mathrm{TiO}_{2}, \mathrm{ZnO}, \mathrm{SnO}, \mathrm{NiO}, \mathrm{Cu}_{2} \mathrm{O}, \mathrm{Fe}_{3} \mathrm{O}_{4}$, and also $\mathrm{CdS}$ have been utilized as photocatalyst for their nontoxic nature, high photosensitivity, wide band gap and high stability. Various process parameters like photocatalyst dose, $\mathrm{pH}$ and initial dye concentrations have been varied and highlighted. Research focused on surface modification of semiconductors and mixed oxide semiconductors by doping them with noble metals $(\mathrm{Pt}, \mathrm{Pd}, \mathrm{Au}$, and $\mathrm{Ag}$ ) and organic matter $(\mathrm{C}, \mathrm{N}, \mathrm{Cl}$, and $\mathrm{F})$ showed enhanced dye degradation compared to corresponding native semiconductors. This paper reviews recent advances in heterogeneous photocatalytic decolorization for the removal of synthetic dyes from water and wastewater. Thus, the main core highlighted in this paper is the critical selection of semiconductors for photocatalysis based on the chemical, physical, and selective nature of the poisoning dyes.
\end{abstract}

\section{Introduction}

\subsection{Photocatalytic Decolorization in Water and Wastewater} Treatment. Generally, dyes are complex unsaturated aromatic compounds with accomplishing characteristics like color, intensity, solubility, fastness, and substantiveness [1, 2]. It could be compounds with different coloring particles, each varying in type from each other in terms of chemical composition, and are used for coloring textiles in different colors and shades that are completely soluble in aqueous media $[2,3]$. Dyes derived from inorganic or organic compounds are called synthetic dyes and they are categorized based on their basic chemistry (Table 1; Figure 1). There are various ways used for the assortment of dyes. It should be noted that each category of dyes has an exclusive chemistry, source of materials, nature of its respective chromophores, nuclear structure, industrial classification, and specific way of bonding. Although some dyes can chemically react with the substrates forming robust bonds in the process, others can be sustained by physical forces. The most common synthetic dyes in use today are dispersible types for polyester dyeing and reactive and direct types for cotton dyeing.

Synthetic dyes are also utilized in high technology applications, like in the electronics, medical, and specifically the nonimpact printing industries. For instance, they are utilized in electrophotography (laser printing and photocopying) in both the organic photoconductor and the toner, in direct and thermal transfer printing, and also in ink-jet printing. With increasing synthetic dye usage, dye removal becomes an important but challenging area of research for wastewater treatment since most of dyes and their degradation products may be carcinogenic and toxic to mammals $[4,5]$. 
TABLE 1: Usage and characterization of dyes.

\begin{tabular}{|c|c|c|c|}
\hline Group of dyes & Characteristics & Application & References \\
\hline Direct dyes & $\begin{array}{l}\text { (i) Dyeing process with one action, without the } \\
\text { assistance of an affixing agent; } \\
\text { simplest and cheapest dyes } \\
\text { (ii) Water soluble anionic dyes; } \\
\text { substantive to form aqueous media in the electrolytes } \\
\text { (iii) High affinity for cellulose fibers } \\
\text { (iv) Apply to the dye materials to improve wash fastness } \\
\text { properties (chelation with salts of metals and treatment } \\
\text { with a cationic dye-complexing resin or formaldehyde) } \\
\text { (v) Some contain sulphonate functionality to improve } \\
\text { solubility (negative charge of dyes and fibers repel each } \\
\text { other) } \\
\text { (vi) Its flat length enable and shape to lie along-side } \\
\text { cellulose fiber and maximum (vii) Van-der-Waals, } \\
\text { hydrogen bonds, and dipole } \\
\text { (ix) Dyeing method: exhaust/beck/continuous }\end{array}$ & $\begin{array}{l}\text { Cotton, cellulosic, } \\
\text { regenerated cellulose, } \\
\text { paper, leather, nylon, } \\
\text { and blends }\end{array}$ & {$[6,7]$} \\
\hline Vat dyes & $\begin{array}{l}\text { (i) Water insoluble dyes } \\
\text { (ii) Apply as soluble leuco salt after reduction in an } \\
\text { alkaline solution with sodium hydrogen sulfide } \\
\text { (iii) The leuco form is reoxidized to the insoluble keto } \\
\text { form to redevelop the crystal structure } \\
\text { (iv) More chemically complex } \\
\text { (v) Dyeing methods: exhaust, package, continuous }\end{array}$ & $\begin{array}{l}\text { Cotton, linen and rayon, } \\
\text { soap }\end{array}$ & {$[8,9]$} \\
\hline Organic pigments & $\begin{array}{l}\text { (i) Negatively charged compounds } \\
\text { (ii) Made from ground up colored rocks, minerals, } \\
\text { animals, and plants } \\
\text { (iii) No chemical information } \\
\text { (iv) Classification based on the dye's source and color } \\
\text { (v) Application requires a mordant }\end{array}$ & $\begin{array}{l}\text { Cotton, paper, cellulosic, } \\
\text { blended fabrics }\end{array}$ & {$[10,11]$} \\
\hline Reactive dyes & $\begin{array}{l}\text { (i) React directly with the fiber molecules to form } \\
\text { chemical bonds } \\
\text { (ii) Conceivable to achieve very high wash fastness } \\
\text { properties } \\
\text { (iii) Require facile dyeing methods } \\
\text { (iv) Simple chemical structure } \\
\text { (v) The largest dye class } \\
\text { (vi) Adsorption spectra with a narrow adsorption band } \\
\text { (vii) Dyeing is bright } \\
\text { (viii) Dyeing methods: exhaust, beck cold pad batch, } \\
\text { and continuous }\end{array}$ & $\begin{array}{l}\text { Cellulosic fabric and } \\
\text { fibers }\end{array}$ & {$[12,13]$} \\
\hline
\end{tabular}

(i) Water insoluble nonionic

(ii) Require additional factors (dye carrier, pressure, and heat) to penetrate synthetic dyes

(iii) Dispersed in aqueous media wherever the dye is dissolved into fibers

(iv) Especially on polyester and to a lesser extent on cellulose acetate, nylon, acrylic fibers, and cellulose (v) Niche market in dye diffusion thermal transfer process for electronic photography and thermal transfer printing

(vi) Dyeing method: high temperature exhaust, continuous

Synthetic/hydrophobic fibers from aqueous dispersion
Silk, wool, synthetic fibers, leather, nylon, modified acrylics, paper, ink-jet printing, food, cosmetics 
TABLE 1: Continued.

\begin{tabular}{|c|c|c|c|}
\hline Group of dyes & Characteristics & Application & References \\
\hline Azoic dyes & $\begin{array}{l}\text { (i) Contain one azo group (mono azo), two azo group } \\
\text { (disazo), three azo (trisazo), four azo group } \\
\text { (tetrakisazo), or more (polyazo) groups } \\
\text { (ii) Attach to two classes of which at least one but } \\
\text { usually both are aromatic } \\
\text { (iii) Exist in the transform } 1 \text { in (iv) which the bond } \\
\text { angle is } 120^{\circ} \text { and the nitrogen atoms are } \mathrm{sp}^{2} \text { hybridized } \\
\text { (v) Consist of electron accepting substituents and } \\
\text { electron donating substituents } \\
\text { (vi) Named as carbocyclic azo dyes if include only } \\
\text { aromatic groups (naphthalene and benzene) } \\
\text { (vii) Named as heterocyclic azo dyes if include } \\
\text { heterocyclic group }\end{array}$ & Printing inks, pigments & {$[18,19]$} \\
\hline Basic dyes & $\begin{array}{l}\text { (i) Water soluble cationic dyes } \\
\text { (ii) Can be applied directly to cellulosic with no } \\
\text { mordants (or metal-like copper and chromium) } \\
\text { (iii) Yield colored cations in solutions } \\
\text { (iv) Apply as brightness of shade is more important } \\
\text { than fastness to washing and light } \\
\text { (v) Some basic dyes show biological activity and are } \\
\text { used in medicine as antiseptics } \\
\text { (vi) Salt-forming counter ion } \\
\text { (vii) Colorless anion of a low molecular mass, organic, } \\
\text { or inorganic acid } \\
\text { (viii) Can be turned to water soluble dye bases by } \\
\text { addition of alkali } \\
\text { (ix) The positive charge is localized on an ammonium } \\
\text { group } \\
\text { (x) Dyeing methods: exhaust, beck, and continuous }\end{array}$ & $\begin{array}{l}\text { Silk, wool, cotton, } \\
\text { polyacrylonitrile, } \\
\text { modified nylons, } \\
\text { modified polyester, } \\
\text { tannin-mordanted } \\
\text { cotton }\end{array}$ & {$[20,21]$} \\
\hline Oxidation dyes & $\begin{array}{l}\text { (i) Primarily aromatic compounds that belong to three } \\
\text { major chemical families (Diamines, Aminophenols } \\
\text { (amino naphthols) and Phenols or naphthols) } \\
\text { (ii) Colorless and are typically a low molecular weight } \\
\text { product } \\
\text { (iii) Categories-oxidation base as a primary, } \\
\text { intermediate and coupler as a secondary, intermediate }\end{array}$ & Hair & {$[22,23]$} \\
\hline Developed dyes & $\begin{array}{l}\text { Any group of direct azo dyes which after applying to the } \\
\text { fiber can be diazotized further and coupled on the fiber } \\
\text { to form shades faster to washing }\end{array}$ & Cellulosic fibers, fabric & {$[24,25]$} \\
\hline Mordant dyes & $\begin{array}{l}\text { A substance utilized to set dyes on fabrics or tissue } \\
\text { sections by forming a coordination complex with the } \\
\text { dye that attaches to the tissue or fabric }\end{array}$ & $\begin{array}{l}\text { Cellulosic fibers, fabric, } \\
\text { silk, wool }\end{array}$ & {$[26-28]$} \\
\hline $\begin{array}{l}\text { Optical/ } \\
\text { fluorescent } \\
\text { brightener }\end{array}$ & $\begin{array}{l}\text { (i) Absorb light in the violet region and ultraviolet } \\
\text { (mostly } 340-370 \mathrm{~nm} \text { ) of the electromagnetic spectrum, } \\
\text { and reemit light in the blue region (usually } \\
420-470 \mathrm{~nm} \text { ) } \\
\text { (ii) Utilized to increase the appearance of color of paper } \\
\text { and fabric, causing a "whitening" effect, making } \\
\text { materials look less yellow by increasing the overall } \\
\text { amount of blue light reflected }\end{array}$ & $\begin{array}{l}\text { Synthetic fibers, leather, } \\
\text { cotton, sport goods }\end{array}$ & {$[29-31]$} \\
\hline Solvent dyes & $\begin{array}{l}\text { (i) Water insoluble } \\
\text { (ii) Free of polar solubilizing groups such as carboxylic } \\
\text { acid, sulfonic acid, or quaternary ammonium }\end{array}$ & $\begin{array}{l}\text { Wood staining, solvent } \\
\text { inks, waxes, coloring } \\
\text { oils, plastic, gasoline oil }\end{array}$ & {$[32,33]$} \\
\hline Anthraquinone & $\begin{array}{l}\text { (i) The oldest dyes ( } 4000 \text { years) } \\
\text { (ii) No natural counterpart } \\
\text { (iii) Low cost effectiveness }\end{array}$ & Wrapping of mummies & {$[34]$} \\
\hline
\end{tabular}


TABle 1: Continued.

\begin{tabular}{|c|c|c|c|}
\hline Group of dyes & Characteristics & Application & References \\
\hline Indigoid & $\begin{array}{l}\text { (i) Expensive } \\
\text { (ii) Made of tyrian purple } \\
\text { (iii) Give progressively paler blue shades } \\
\text { (iv) Oxidation process of indigoid gives phenylacetic } \\
\text { acid }\end{array}$ & $\begin{array}{l}\text { Textile, wool, linen, } \\
\text { cotton } \\
\text { Use exclusively for } \\
\text { dyeing denim jeans, } \\
\text { jackets }\end{array}$ & {$[35]$} \\
\hline Sulfur dyes & $\begin{array}{l}\text { (i) Made by heating aromatic or heterocyclic } \\
\text { compounds with species that release sulfur or sulfur } \\
\text { (ii) Classified by sulfur bake, polysulfide melt dyes, and } \\
\text { polysulfide bake } \\
\text { (iii) Not well-defined chemical compounds } \\
\text { (iv) Mostly contain various thiophenolic and } \\
\text { heterocyclic sulfurs } \\
\text { (v) On oxidation, the monomeric molecules } \\
\text { cross-linked into large molecules form disulfide bridge } \\
\text { (vi) Dyeing methods: continuous }\end{array}$ & Cotton, other cellulosic & {$[36]$} \\
\hline
\end{tabular}

\section{Dye technologies}

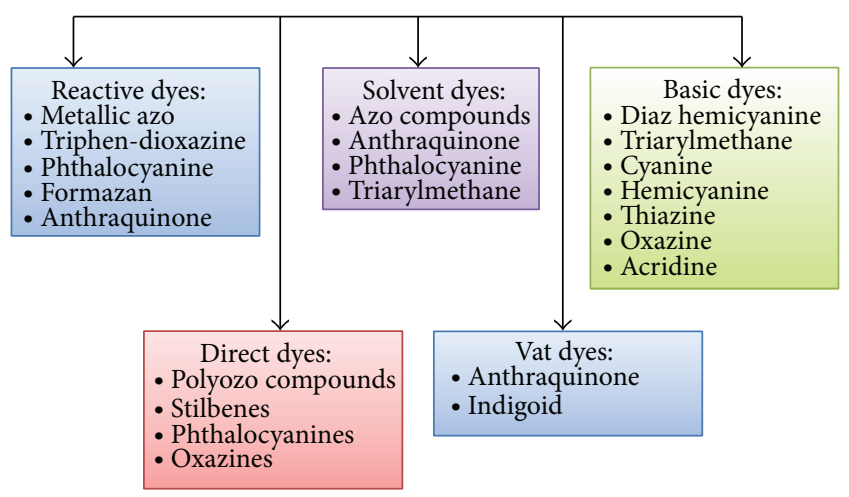

FIgURE 1: Synthetic dyes and its derivatives.

Heterogenous photocatalysis using semiconductors for water and wastewater treatment continues to attract much interest $[4,5,37,38]$. The lower cost of catalysts and the utilization of environmental protection and renewable energy form this technology to be adequately attractive compared to other techniques [37]. Because the process relies on the photoactivation of semiconductors, the efficiency of the catalyst is qualified by the capacity to generate electronhole pairs in addition to radical production $[39,40]$. Hence, the selection of proportionate semiconductors is the key to reactivity control [38].

1.2. Poisoning Dyes. Only 45 to $47 \%$ of dyes have been reported as organic dyes with biodegradable and solubility characteristics. The remaining 55 to $53 \%$ of dyes are toxic and their persistence in wastewater has recently become an issue of interest $[8,41,42]$. Synthetic or poisoning dyes engaged more often on industrial scale are acid dyes, water soluble anionic, basic dyes-water soluble cationic, substantive dyes-alkaline, vat dyes-water soluble alkali metal salt, azoic dyes, sulfur dyes, and chrome dyes.
Generally, there are two important components in the dye molecules: chromophore component that is responsible for producing the color and the auxochrome component which increases the affinity of the dye towards cellulose fibers $[14,43]$.

The mentioned dyes are released in aqueous streams as effluents of several industries, including textiles, paper, leather, plastic, automobile, furniture, finishing sector, and others, which consequently create intense environmental pollution problems via the release of potential carcinogenic and toxic substances into the aqueous phase $[22,23]$. The discharge of an enormous volume of wastewater containing dyes is an inevitable consequence, because the textile industry consumes large quantities of water and all dyes cannot be completely combined with fibers during the dyeing process. More than 79105 metric tonnes of dye stuffs are produced worldwide annually, with 10 to $50 \%$ of this amount being released into wastewater $[18,44]$. These high concentrations of dyes in effluents interfere with the penetration of visible light into the water, resulting in a hindrance to photosynthesis and a decrease in gas solubility, since less than $1 \mathrm{mgL}^{-1}$ of dye is highly visible. Furthermore, synthetic dyes, which include an aromatic ring in their basic structure, are regarded as toxic, carcinogenic, and xenobiotic compounds [43-46]. Also, this type of dyes may convey toxicity to aquatic life and may be mutagenic and carcinogenic and can cause intense damage to human beings, including the reproductive system and dysfunction of the kidneys, brain, liver, and central nervous system [34].

Therefore, decolorization and detoxification of dyecontaining wastewater need to be conducted before discharging wastewater into natural water bodies $[26,27,29]$. Certain physical, chemical, and biological treatments are currently being used for dye wastewater treatment. Although physical and chemical methods usually show high dye-removal efficiencies, high operating costs are the main drawback due to the large-scale application of these methods [32, 47, 48]. Furthermore, due to the high chemical stability of synthetic dyes, conventional biological treatment using bacteria cannot remove the dyes efficiently $[43,49,50]$. 


\section{Photocatalytic Decolorization of Synthetic Dyes}

The complete degradation of the dyes is not possible by conventional methods such as precipitation, adsorption, flocculation, flotation, oxidation, reduction, electrochemical, aerobic, anaerobic, and biological treatment methods. These methods have inherent limitations in technologies such as less efficiency and production of secondary sludge, the disposal of which is a costly affair [43-53]. Merely, transferring hazardous materials from one medium to another is not a long-term solution to the issue of toxic waste loading on the environment [30]. Many technologies have been applied to remedy dyes from wastewater, like coagulation/flocculation, biological treatment, electrochemical, membrane filtration, ion exchange, adsorption, and chemical oxidation [54, 55]. Chemical coagulations for dye removal require loading of chemical coagulation and optimal operating conditions like $\mathrm{pH}$ and coagulation dosage should be rigidly reminded for achieving maximum dye removal [56]. The coagulationflocculation process can be utilized as a pre- or post- or even as a main treatment. This process is cost effective and easy as it consumes less energy than the conventional coagulation treatment [57]. However, utilizing inorganic salts like aluminum chloride and aluminum sulfate as the coagulation agent has now become controversial because of their possibility of contributing to Alzheimer's disease [56-58]. Polyacrylamide-based materials are also often utilized in the coagulation process, but the possible release of monomers is now considered damaging due to their entering into the food chain and causing potential health impacts (e.g., carcinogenic effects).

Adsorption removal method is a simple and effective method/design since it is easy to use and can be implemented for dye treatment even in small plants; however, it usually produces huge amounts of sludge, especially in the wastewater with high dye concentrations [59]. Adsorption of dyes on many adsorbents (e.g., $\mathrm{SiO}_{2}, \mathrm{Al}_{2} \mathrm{O}_{3}, \mathrm{CaO}, \mathrm{MgO}$, $\mathrm{Fe}_{2} \mathrm{O}_{3}, \mathrm{Na}_{2} \mathrm{O}, \mathrm{K}_{2} \mathrm{O}$, bentonite, and montmorillonite) has been broadly studied, but the activated carbon has been proven to be the most effective catalyst due to its high specific surface area, ultra high adsorption capacity, and low selectivity for both nonionic and ionic dyes. However, it has some limitations, including the need for regeneration after exhausting, high cost of the activated carbon, and the lack of adsorption efficiency after regeneration $[59,60]$. Taking all these facts into consideration, much of the present work involves the degradation and mineralization of synthetic dyestuff in industry by heterogenous photocatalyst.

The heterogenous photocatalyst relates to the water decontamination processes that are concerned with the oxidation of biorecalcitrant organic compounds $[4,61,62]$. This impressive method relies on the formation of highly reactive chemical species that degrade a number of recalcitrant molecules into biodegradable compounds and is known as the advanced oxidation process (AOP).

The Environmental Protection Agency (EPA) has approved the inclusion of AOP as the best available technology to meet the standard with specifications that provide safe and sufficient pollution control of industrial processes and remediation of contaminated sites $[42,63]$.

Advanced oxidation processes are based on the production of hydroxyl radicals which oxidize a wide range of organic pollutants including dyes quickly and nonselectively. AOPs include homogenous and heterogeneous photocatalytic oxidation systems. The homogenous photocatalytic oxidation system employs various oxidants such as $\mathrm{H}_{2} \mathrm{O}$, $\mathrm{O}_{3}$, Fenton reagent, $\mathrm{NaOCl}$, and many others either alone or in combination with light [64] (Figure 2). Recently, heterogeneous photocatalysis has emerged as an important degradation technology leading to the total mineralization of organic pollutants, especially synthetic dyes $[5,37,38,65,66]$.

\subsection{Photocatalytic Decolorization of Acid Dyes-Water Soluble} Anionics. Acid dyes are chemically a sodium (less often ammonium) salt of a carboxylic or phenol organic acid, or sulfuric acid, with ionic substitution to be soluble in water and contains affinity for amphoteric fibers, while lacking direct dye affinity for cellulose fibers (via hydrogen bonding, Van de Waals, and ionic bonding) $[67,68]$. Acid dyes consist of several compounds from the most varied categories of dyes, which represent characteristic differences in structure (e.g., nitro dyes, triphenylmethane, and anthraquinone) [69]. Acid dyes are commonly divided into several classes which depend on level dyeing properties, fastness requirements, and economy, which are indicated by the strength of the anionic characteristic of dyes to the cationic sites of the cellulose fibers [68]. Most of acid dyes are generated from chemical intermediates, where anthraquinone-like structures and triphenylmethane predominate as the final state, which give blue, yellow, and green color [68-70].

Acid dyes, just as any of the synthetic dyes, have the capability of persuading sensitization in humans because of their complex molecular structure and the way in which they are metabolized in the body. Moreover, their water solubility is harmful to human beings since they are sulphonic acids [71]. The sulphonate groups are spread evenly along the molecule on the opposite side to the hydrogen bonding -OH groups, to minimize any repulsive effect [69]. This in consequence determines the main problem with anionic dyes, which is the lack of fastness during the washing and removing process.

Thus, many research works have paid increasing attention to the degradation of acid dyes in the water stream in recent years. Several techniques, including the use of activated carbon, membrane filteration, adsorption, and coagulation have been known to unravel the problems caused by the presence of acid dyes (Table 2).

However, due to the recalcitrant nature of acid dyes and the high salinity of wastewater containing acid dyes, these conventional treatment processes are feckless. Adsorption and coagulation methods have also been applied to treat acid dyes in wastewater, which always result in secondary pollutants [66]. Furthermore, it is noted that acid dyes have $-\mathrm{SO}^{3-},-\mathrm{COOH},-\mathrm{OH}$, and hydrophilic groups and excellent solubility in the water stream $[74,75]$. Their molecules spread linearly in solution and have a notable tendency to aggregate 
TABLE 2: Types of adsorbents used with different anionic/acid dyes.

\begin{tabular}{|c|c|c|}
\hline Adsorbent & Anionic dyes & References \\
\hline \multirow{3}{*}{ Organo-bentonite } & Acid scarlet & {$[72]$} \\
\hline & Acid turquoise blue & {$[73]$} \\
\hline & Indigo carmine & [74] \\
\hline \multirow{4}{*}{ Ammonium functionalized mesoporous materials } & Reactive brilliant red & [75] \\
\hline & Acid fuchsine & {$[76]$} \\
\hline & Orange IV & [77] \\
\hline & Methyl orange (MO) & [78] \\
\hline Apatitic tricalcium phosphate & \multirow{2}{*}{ Reactive yellow 4} & [79] \\
\hline Apatitic octocalcium phosphate & & {$[80]$} \\
\hline Wood shaving bottom ash & Red reactive 141 & [81] \\
\hline Bagasse ash & Acid blue 80 & [82] \\
\hline
\end{tabular}

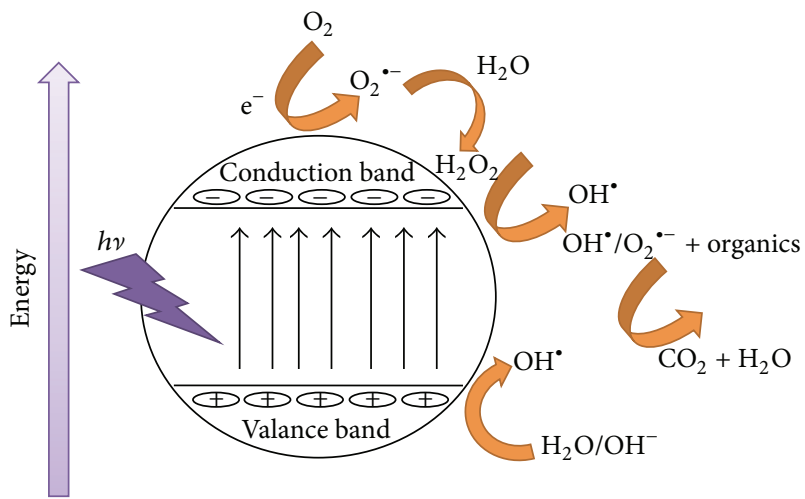

FIGURE 2: General view on photocatalytic mechanism and degradation process.

by hydrogenous bonding, and consequently form colloids in solution and also tend to be adsorbed and flocculated [81]. To overcome such limitations, photocatalytic decolarization of acid dyes water soluble is essential. This process done through the formation of electron-hole pairs with proper photon energy. It has been assumed that once the energy is larger than the band gap, the electron-hole pairs are separated between the semiconductor's valence and conduction bands $[61,82]$. The acid dyes as adsorbed species on suitable sites on the surface of semiconductors undergo photooxidation, reduction, and synthesis under either ultraviolet, sunlight, or even ultrasonic lights. In addition, the aromatic linkages are susceptible to reduction under light irradiation [83] (Figure 3).

This encourages a promising technology based on the advanced oxidation process that has been studied extensively through a broad range of acid dyes that can be nonselectively oxidized quickly $[43,84,85]$. Photocatalysis of acid dyes entails the formation of adequate concentrations of highly reactive transitory species like hydrogen peroxide, hydroxyl radicals, and superoxides to react with acid dyes and degrade them in the presence of a semiconductor and visible light or ultraviolet (UV) light [86]. Usually the semiconductors with band gap energy of $3.2 \mathrm{eV}$ are used as photocatalysts with

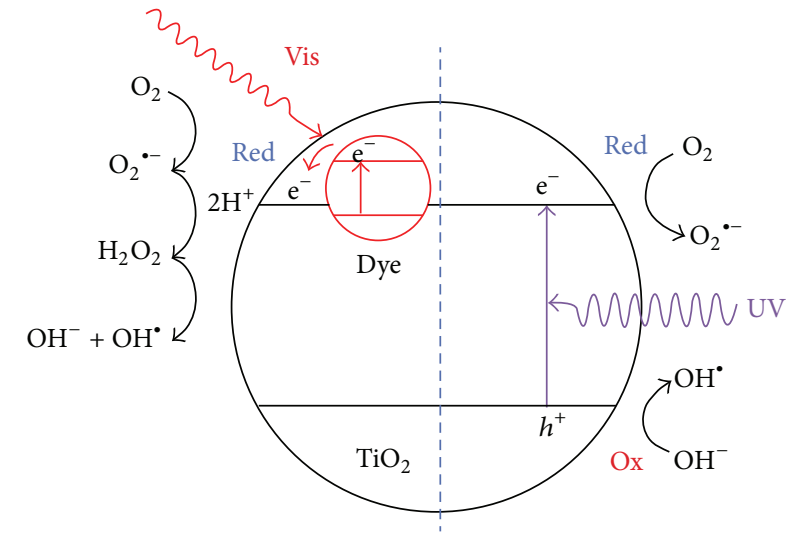

FIgURE 3: The photocatalytic decolorization of $\mathrm{TiO}_{2}$ towards Acid Red 44 as a model of acid dyes [83].

the assumption that as a proton at equal or higher energy $(\lambda<400 \mathrm{~nm})$ illuminates the semiconductor, the photon energy creates an electron to jump from the valence band to the conduction bands, generating electrons and positively charged holes [51, 87]. These electron-hole pairs persuade a series of reactions, which oxidize the dye acids.

Among the various semiconductor oxides, $\mathrm{TiO}_{2}$ and $\mathrm{ZnO}$ have been intensively investigated since the discovery of their ability to photocatalyse acid dyes [37]. Briefly, once the aqueous semiconductor $\left(\mathrm{TiO}_{2}\right.$ and/or $\left.\mathrm{ZnO}\right)$ suspensions are irradiated in light energy greater than the band gap energy of the semiconductors, conduction band electrons and valence band holes are generated $[51,88,89]$. As the charge separation is maintained, the electrons and holes may migrate to the semiconductor surface where it takes part in the redox reaction with acid dyes [90-92]. The photogenerated electrons react with the adsorbed acid dye molecules $\left(\mathrm{O}_{2}\right)$ on the semiconductor site and diminish it to superoxide radical anion $\left(\mathrm{O}_{2}{ }^{\circ}\right)$ while the photogenerated holes oxidize the $\mathrm{H}_{2} \mathrm{O}$ or $\mathrm{OH}^{-}$ions adsorbed at the semiconductor surface to $\mathrm{OH}^{\bullet}$ radicals $[43,93-95]$. These generated radicals with other highly oxidant species act as strong oxidizing agents which could easily attack the adsorbed acid dye molecules or those located close to the surface of the semiconductor, thus 
resulting in complete degradation of acid dyes into its smaller biodegradable fragments $[89,96]$.

Despite the many benefits of using $\mathrm{TiO}_{2}$ and $\mathrm{ZnO}$ as a photocatalyst to degrade the dye acids, if the aim is to expand a solar-powered treatment technology, there are few disadvantages of the technology that barricade commercialization. Even if both semiconductors offer high absorption and surface areas, they can be adjusted by preparation parameters $[84,97,98]$. Although many acid dyes can be effectively photodecomposed using $\mathrm{TiO}_{2}$ and/or $\mathrm{ZnO}$ as the photocatalyst, the kinetics and mechanism of photocatalytic decolorization with respect to both semiconductors as photocatalysts are comparatively unclear. It has been recorded that both semiconductors can contribute to the decomposition reaction in different ways without decreasing their activity over time [99]. Several kinetic models for catalyzed oxidation utilizing heterogenous catalyst supported by both organic and inorganic carriers have been published in the literature $[51,83,100]$. However, only a few kinetic models of catalyzed photocatalytic decolorization of acid dyes were published. The Mars-Van Krevelen mechanism stated that the surface of the semiconductor catalyst acted as redox mediator, which transferred electrons to oxygen to form oxygen anions as radicals, $\mathrm{O}_{2}{ }^{-\bullet}$. The $\mathrm{O}_{2}{ }^{-\bullet}$ anion radical oxidized the adsorbed acid dye compounds to form various products, while the reduced form of $\mathrm{O}_{2}{ }^{-}$could be regenerated by gaseous oxygen $[61,101]$. The stationary-state adsorption mechanism was based on the steady-state assumption and also the oxidation reduction of the adsorbed phase [102]. The Ely-Rideal mechanism envisaged that a heterogeneous reaction took place among strongly chemisorbed acid dye atoms and physically adsorbed molecules which become attached to the surface by faint Van der Waals forces [84]. The Langmuir-Hinshelwood mechanism is based on the reaction that occurred between both acid dyes and semiconductors $[95,103]$.

\subsection{Photocatalytic Decolorization of Basic Dyes-Water Soluble} Cationics. Water soluble basic dyes are commonly considered as the most difficult to eliminate or degrade from the dyeing effluent, because of their high stability and resistance ability in the water stream [104-106]. Basic dyes possess cationic functional groups such as $-\mathrm{NH}^{3+}$ or $=\mathrm{NR}^{2+}$ [105]. Both of these protein functional groups in basic conditions generate a negative charge as the $-\mathrm{COOH}$ groups are deprotonated to give $-\mathrm{COO}^{-}$[107]. Basic dyes perform weakly on natural fibers but work very well in acrylics [105]. Basic dyes will form a covalent bond with the proper polyacrylic functionality, and once attached, these basic dyes are very difficult to remove [106]. Cationic triphenylmethane dyes are one of the most extensive basic dyes utilized as colorants and antimicrobial agents in different industries. Previous articles demonstrate that it may further serve as targetable sensitizers in photodestruction of specific cellular components or cells $[107,108]$. Methyl green (MG) is a basic triphenylmethane and dicationic dye frequently utilized for staining of solutions in biology and medicine. It is also utilized as a photochromophore to sensitize gelatinous films [109]. The increasing interest in the development of modern and new methodologies for the degradation of toxic basic dyes has led to the deduction that the most effective way for oxidation of the basic dyes is with a powerful oxidizing agent, specifically when a free radical like ${ }^{\circ} \mathrm{OH}$ is generated [110-112] (Figure 4).

Lately, advanced oxidation processes have been broadly investigated and have become alternative methods for decolorizing and reducing recalcitrant wastewaters generated by basic dyes. Likewise, the use of cadmium oxide (CdO) nanostructure as one of the promising semiconductors for this operation demonstrates positive results [113-115]. CdO is an n-type semiconductor with a direct band gap of 2.2 to $2.5 \mathrm{eV}$ and an indirect band gap of 1.36 to $1.98 \mathrm{eV}$ [114]. Since CdO has a band gap tailored to the visible region of solar light with a similar photocatalytic mechanism to semiconductor oxides, it can be an important option as photocatalyst materials especially in the decolorization process of basic dyes [45, 113]. Indeed, the evaluation of photocatalytic activity of CdO towards basic dyes is considered as cauliflower-like [116]. The nanostructure of $\mathrm{CdO}$ for removing the basic dyes from aqueous solution has been reported and it is believed that the crystal orientation, morphology, crystallinity, particle size, architecture types, and oxygen defects play an important role in changing the band gap. Actually, diversity in the band gap energy is highlighted to lattice defects because of the Burstein-Moss effect. Besides, the catalytic, optical, and electrical properties originate from the difference of band gaps in different structures [115]. Thus, it is critical to probe an investigation on the generation of new $\mathrm{CdO}$ structures for better photodegradation of basic dyes. Different structures of $\mathrm{CdO}$ on a nanoscale have been reported, such as nanowires, nanoparticles, nanoneedles, thin film, nanocrystal, and others [117]. CdO micro- and nanoarchitectures with three-dimensional structures such as rods, tubes, and cauliflower-like structures have a larger specific surface area and enhanced oxygen vacancy, which in turn increases the degree of oxidation process on basic dyes [118]. Cauliflowerlike architectures have attracted great interest due to its special and novel morphology with high specific surface area that can facilitate the diffusion and mass transportation of the basic dye molecules in photodegradation applications [116]. This particular structure can be easily synthesized using mechanochemical methods, a cheap process, followed by thermal treatment conforming to the detailed process presented in former studies.

Most studies related to photodegradation techniques have been done using $\mathrm{TiO}_{2}$ and/or $\mathrm{ZnO}$ as the model photocatalyst because of their nontoxicity, cheapness, chemical stability, and high photocatalytic activity [37, 119-121]. The photocatalytic decolorization of basic dyes with $\mathrm{TiO}_{2}$ and/or $\mathrm{ZnO}$ as the charge carrier or generation is summarized in Figure 2. The $\mathrm{OH}^{\circ}$ or the directly produced charge is a strong oxidizing agent which attacks basic dyes present at or near the surface of the semiconductor [122]. It ultimately causes the complete degeneration of the basic dyes into harmless compounds. In general, two different types of $\mathrm{TiO}_{2}$ phase are normally used in photocatalytic decolorization of basic dyes: anatase $(3.2 \mathrm{eV})$ and rutile $(3.0 \mathrm{eV})$. The adsorptive affinity of anatase for the basic dyes is higher than that of rutile, and thus anatase 


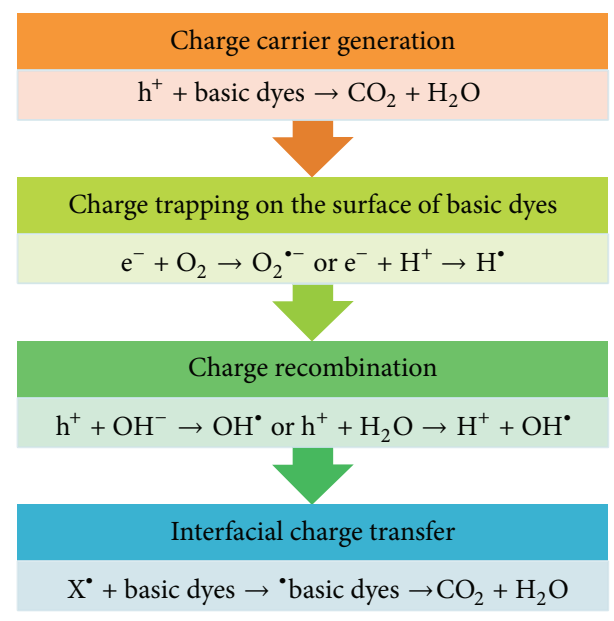

FIGURE 4: The steps in the photocatalytic process of basic dyes using $\mathrm{TiO}_{2}$ or $\mathrm{ZnO}$.

is generally regarded as the more photocatalytic active phase of $\mathrm{TiO}_{2}$, presumably due to the combined effect of lower rates of recombination and higher surface sites [123, 124].

The dye derivative reactive brilliant blue (KN-R) has been broadly utilized as a model of basic dyes in the photocatalysis process. The effects of key operational factors like reaction $\mathrm{pH}$, catalyst loading, $\mathrm{H}_{2} \mathrm{O}_{2}$ dosage, and the initial basic dye concentration on the decolorization were extensively studied to optimize the process for maximum degradation of basic dyes [125]. It can be concluded that the photocatalytic decolorization process performed a fast oxidation without the formation of polycyclic products and intermediate products at a suitable wavelength of light $[51,126]$. The reactions frequently take place on the surface of the semiconductors. Hence, the need for a semiconductor supported by a good adsorbent is much felt because of the power to concentrate pollutants near semiconductor particles and the capacity for adsorption of generated intermediates and the capability of reusing adsorbents [127]. In addition, to ensure full use of the solar energy source, it is of great interest to develop photocatalysis of basic dyes for expansion of the adsorption to the visible light range. For both $\mathrm{TiO}_{2}$ and/or $\mathrm{ZnO}$, a great deal of effort has been focused to extend their photoadsorption to the visible light range, for example, by doping with anions of $\mathrm{C}, \mathrm{S}$, and $\mathrm{N}$ or transition metal cations [128, 129]. Besides $\mathrm{TiO}_{2}$ and/or $\mathrm{ZnO}$, a great deal of attention has also been focused in the search for semiconductor oxides of $\mathrm{Bi}_{2} \mathrm{WO}_{6}, \mathrm{BiM}_{\text {ox }} \mathrm{O}_{6}, \mathrm{Bi}_{2} \mathrm{M}_{\text {ox }} \mathrm{W}_{1-x}$, and $\mathrm{Bi}_{4} \mathrm{Ti}_{3} \mathrm{O}_{12}$ which have been recently revealed to exhibit photocatalytic activity and decolorization of basic dyes in the visible light range owing to their lower band gap than that of $\mathrm{TiO}_{2}$ and/or $\mathrm{ZnO}[130-$ 140].

2.3. Photocatalytic Decolorization of Disperse Dyes-Alkaline. Disperse dyes have low solubility in water. However, they can interact with the polyester chains by forming dispersed particles. Their main application is the dyeing of polyester, and they find less use in dyeing cellulose acetates and polyamides [141-145]. The general structure of disperse dyes is planar, small, and nonionic, with attached polar functional groups such as $-\mathrm{NO}_{2}$ and $-\mathrm{CN}$. In addition, this type of dyes is a mitotic toxication agent and should be considered as a biohazard component [142]. Thus, discharge of disperse dyes have become a subject of concern in the universe due to its harmful and toxic effects to living organisms and the environment [143]. As far as the wastewater treatment technologies are concerned, different techniques have been utilized for the reduction and degradation of dispersed dyes such as chemical precipitation, $\mathrm{H}_{2} \mathrm{O}_{2}$ adsorption, oxidation by chlorine, electrochemical treatment, ozone electrolysis, adsorption, ion pair extraction, flocculation, coagulation, membrane filtration, and specially the photocatalytic process [145-147].

The dispersed dyes (alkaline compounds) can be most effectively decomposed by photocatalytic methods [148150]. Recently, owing to their unique and special electrical and optical properties, semiconductor materials have gained global acceptance for alkaline dispersed dye treatments [151]. It has been demonstrated that the photooxidation of $\mathrm{CN}$ to OCN occured during the photodegradation of alkaline dyes in the presence of powerful oxidation agents [152-154]. Considering that disperse alkaline dyes cannot be treated by conventional biological processes, intensive investigations on the latest treatment techniques of these wastewaters have been conducted to develop effective methods for the remediation and treatment of a wide variety of alkaline-dye pollutants owing to their capability to produce a complete degradation process. The photocatalytic degradation reaction is usually conducted for compounds dissolved in water-like alkaline dyes, at mild temperature and pressure conditions, utilizing ultraviolet-illuminated semiconductor powders without the requirements of expensive oxidants [86, 155-158] (Figure 5).

A semiconductor is generally characterized by the band gap energy between its electronically populated valence band and its broadly vacant conduction band [33].

Copper oxide $(\mathrm{CuO})$ is a one of the most promising semiconductors used in advanced oxidation processes for degradation of alkaline dyes [159-161]. With an energy band gap of 1.21 to $1.5 \mathrm{eV}$ it has the ability to perform under irradiation in sunlight. Reactions involving $\mathrm{Cu}^{+} / \mathrm{Cu}^{2+}$ lead to the oxidative transformation of alkaline dyes. The unique electronic structure of $\mathrm{Cu}$ allows for the interaction with the spin restricted $\mathrm{O}_{2}$ enabling $\mathrm{Cu}$ to participate in the redox reaction with alkaline dyes [162]. Many researchers have anticipated the reaction of $\mathrm{CuO}$ on different adsorbents like activated alumina, zeolite, or activated carbon in wastewater treatments. It was found that in order to achieve an efficient, stable, and economical catalyst, $\mathrm{CuO}$ semiconductors must be fixed on an ideal and an inert support [163-165]. Among all $\mathrm{CuO}$ supported systems for alkaline dye photodecolorization, zeolite was found to be the most ideal with several distinct advantages, including super adsorption capability, unique uniform pores, and special ion-exchange capability [166]. 


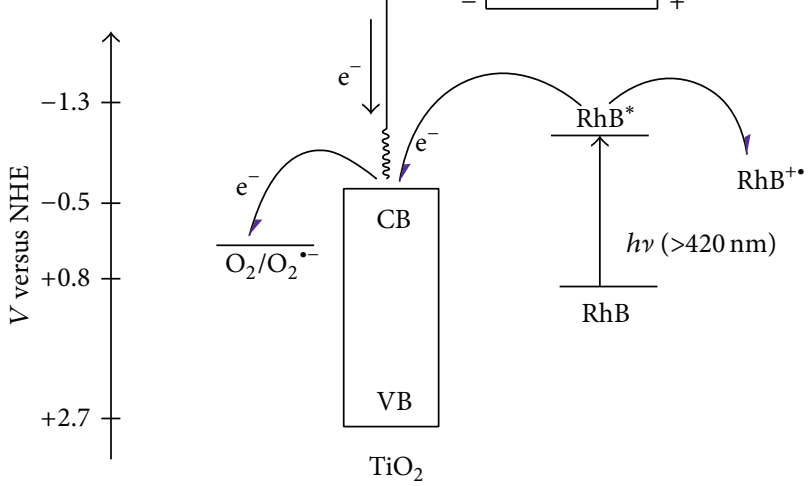

FIGURE 5: Proposed mechanism of the photoelectrocatalytic degradation of Rhodamine $\mathrm{B}$ with $\mathrm{TiO}_{2}$ as the electrode [155].

\subsection{Photocatalytic Decolorization of Vat Dyes-Water Soluble} Alkali Metal Salts. Almost 22\% of the total volume of industrial wastewater produced comes from the textile industry, with $7 \times 10^{5}$ tonne of materials classified as vat dyes or water soluble alkali metal salts $[167,168]$. This type of dyes produces undesirable effluents and is discharged into the environment without further treatment. Once the vat dyes enter natural water bodies, it can cause intense problems if not treated, since the dyes are toxic, mutagenic, and carcinogenic to human life as well as can inhibit photosynthesis of aquatic life even in quantities as low as $1 \mathrm{ppm}$ [169]. To solve this problem, several semiconductors for oxidative photodecolorization have been tested, including $\mathrm{WO}_{3}, \mathrm{TiO}_{2}, \mathrm{MnO}, \mathrm{CuS}, \mathrm{ZnO}$, $\mathrm{Fe}_{2} \mathrm{O}_{3}, \mathrm{ZrO}_{2}, \mathrm{CuO}, \mathrm{CdS}, \mathrm{ZnS}, \mathrm{In}_{2} \mathrm{O}_{3}, \mathrm{SnO}_{2}$, and $\mathrm{Nb}_{2} \mathrm{O}_{5}[170$ 176].

The selection of the type of semiconductor is based on its ability to convert the vat dyes into nontoxic products [44, $90,177,178]$. Additionally, the use of mesoporous materials, like zeolite as a support for these series of semiconductors, has recently become the focus of intensive research on vat dye photodecolorization, due to the fact that the semiconductor support influences the photocatalytic efficiency through structural features, and the interaction between the vat dyes leads to the enhancement of contact between the surface, and irradiation likewise decreases with the amount of semiconductor required [179]. Thus, there are some studies focused on the importance of semiconductor supported zeolite for vat dye photodegradation, including Co-ZSM- $5, \mathrm{TiO}_{2}-\mathrm{HZSM}-5$, Fe-exchange zeolite, and $\mathrm{CuO}-\mathrm{X}$ zeolite $[180,181]$.

$\mathrm{TiO}_{2}$ has been the most studied material for the photocatalysis of vat dyes [182-186]. $\mathrm{ZnO}$ has also been identified to be the main contender whose physicochemical properties are comparable to those of $\mathrm{TiO}_{2}$. However, $\mathrm{ZnO}$, just as with $\mathrm{TiO}_{2}$, suffers from its large band gap energy that is close to $3.2 \mathrm{eV}$, which limits its adsorption of solar light emission that reaches the earth to less than 3 to $4 \%$. For both semiconductor materials, the valence band is composed of $\mathrm{O}^{2-}$ (2p orbital), which is of anionic character, that induces interactions and oxidation composition with the vat dyes (alkali metal salts) [187-190]. However, this anionic character gains rapid recombination and holes during the oxidation process and in turn diminishes the efficiency of the photocatalytic reaction $[191,192]$. From this viewpoint, efforts have been allocated to extend the adsorption of $\mathrm{TiO}_{2}$ and $\mathrm{ZnO}$ to deal with the photosensitization by vat dye molecules. According to the literature, reports on $\mathrm{ZnO}$ for the vat dye photodegradation are still scarce. The nanosized $\mathrm{ZnO}$ has extracted intense interest in recent years, especially in vat dye photodegradation for enhancing its performance, such as changes in surface properties and increase in surface area as well as in quantum effects of the overall decolorization process [193-195]. Upon light irradiation, this nanosized $\mathrm{ZnO}$ produced a highly active radical species that can quickly oxidize the vat dyes into harmful residues.

Copper sulfide (CuS) is another type of semiconductor that is currently used in photocatalytic decolorization of vat dyes [196-199]. CuS with a layered structure is a transparent p-type semiconductor with a band gap above $3.1 \mathrm{eV}$ [198]. The top of the valence band is principally composed of wellhybrid state of $\mathrm{Cu} 3 \mathrm{~d}$ and S-3p states, while the bottom of the conduction band consists primarily of $\mathrm{Cu} 4 \mathrm{~s}$ state $[196,197]$. The band gap of $\mathrm{CuS}$ was recognized to be a direct-allowed transition type through the analysis of the symmetry [199]. This small dispersion of the conduction band leads to the broadband gap and high stability of $\mathrm{CuS}$ to be more convenient for vat dye adsorption and oxidation.

2.5. Photocatalytic Decolorization of Azoic Dyes. The azoic dyes that are normally used on industrial scale have characteristics that are dependent on one or more azo bonds ($\mathrm{N}=\mathrm{N}-$ ) with aromatic rings $[167,200-202]$. The aromatic ring system of the dyes helps to strengthen the Van-der-Waals forces between dye and fibers [203]. Most synthetic dyes have significant structural variations and are extremely stable in performance under light and washing and most severely are resistant to aerobic biodecolorization by bacteria [204, 205]. Thus, it has been reported that the effluents from textile or dye industries involve aromatic compounds which are chemically stable and harmful to human health [201]. Various substitutions on the aromatic nucleus and most versatile groups of compounds give structurally diverse which make them recalcitrant, xenobiotic, noticeable in public, teratogenic, and resistant to degradation [204]. The amount of azo dye concentrations present in wastewater varied from very low to high concentrations ( 5 to $1500 \mathrm{mgL}^{-1}$ ) that leads to color dye effluents causing toxicity, including carcinogenic and mutagenic effects in biological ecosystems. In addition, under anaerobic conditions acid dyes are promptly decreased to potentially hazardous aromatic amines [206]. Therefore, water soluble azo dyes even at low concentrations can cause water streams to be highly colored. On the other hand, azo dyes are insoluble in water but may become solubilised by alkali reduction, for instance, by sodium dithionite which is a reducing agent in the presence of sodium hydroxide [207]. Hence, they tend not to contain several functional groups which may be assailable to oxidation and reduction, which in turn gives harmful effects to the water stream habitat. 
The biological approach of the decolorization of azo dyes takes place either by adsorption on the microbial biomass such as fungi, algae, yeast, and bacteria, along with anaerobic to aerobic treatments or biodegradation by the cell [208]. Azo dyes can also be reduced chemically by sulfide and dithionite. The decolorization mechanism of azo dyes based on the extracellular chemical reduction with sulfide was postulated for sulfate reducing environments [209]. However, it has also been noted that for the treatment of azo dyes containing wastewater, traditional methods like flocculation, adsorption onto activated carbon, activated sludge process, and reverse osmosis have difficulties in complete degradation of pollutants and also have the further disadvantage of resulting in secondary pollution [208-210]. Moreover, anaerobic decolorization of azo dyes may also produce carcinogenic aromatic amines.

Therefore, the photocatalytic oxidation technique has received significant attention for destroying of azo dyes in recent years. This technique can be divided into homogenous and heterogeneous subgroups, based on the action of $\mathrm{OH}^{\bullet}$ which enables almost complete mineralization of azo dyes under mild experimental conditions due to the high oxidation potential [211-215]. In heterogeneous photocatalysis of azo dyes, the electron-hole pairs will be initially produced by irradiation of a semiconductor with a photon of energy equivalent to or greater than its band gap width [213]. The electrons and holes may migrate to the semiconductors on the catalyst surface where they take part in redox reactions with the adsorbed azo dyes [212]. The oxidizing radicals could attack the azo dye molecule and disintegrate it into $\mathrm{CO}_{2}$ and $\mathrm{H}_{2} \mathrm{O}$ molecules which are nontoxic [212-214]. It has been suggested that the formation of free radicals acts as a primary oxidizing species [216]. The mechanism on photodecolorization of azo dyes with methyl red and methyl orange as a model of compound is illustrated in Figures 6 and 7 , respectively.

It is claimed that azo dyes are noted for their photocatalytic decolorization in the absence of oxygen whenever a suitable electron donor or hydrogen source is present [217]. Structurally, azo dyes are double bonded belonging to different chromophoric groups and are heterocyclic and adsorb visible light [208]. The reduction of the chromophoric group shifts the visible region of the ultraviolet or infrared region, and thus a reduction in color is achieved. Consequently this phenomenon has encouraged several research works using heterogenous semiconductor photocatalysts like $\mathrm{TiO}_{2}, \mathrm{ZrO}_{2}$, $\mathrm{SnO}_{2}, \mathrm{Fe}_{2} \mathrm{O}_{3}, \mathrm{CuO}, \mathrm{ZnO}$, and $\mathrm{CdSas}$ as an alternative to conventional methods for the degradation of azo dyes from wastewater streams [218-220]. The degradation of hydrophobic and hydrophilic azo dyes has been demonstrated to be effective in acetone solution under exposure to UV light.

Recently, photocatalysis of azo dyes using solar or artificial light and $\mathrm{TiO}_{2}$ has been the objective of several studies as it is an attractive low energy strategy that has been applied to many other organic compounds (e.g., phenol) [4]. $\mathrm{TiO}_{2}$ is chemically inert, corrosion resistant, and most importantly, it works under mild conditions without any chemical additives [221, 222]. Meanwhile, it was found that in degradation of methyl orange or 4-4-[(dimethylamone)phenylazo] benzenesulfonic acid, a $\mathrm{TiO}_{2}$ film was up to $50 \%$ less effective than the $\mathrm{TiO}_{2}$ slurry. However, some improvements were observed after coating/doping the $\mathrm{TiO}_{2}$ film with metals, but the films were still not as impressive as the slurry [223, 224]. Meanwhile, other studies have shown that only cationic azo dyes can be adsorbed on the surface of the photocatalyst and simultaneously their photocatalytic degradation was quicker than the degradation of anionic azo dyes like Eriochrome Black T $[225,226]$. It has been found that $\mathrm{TiO}_{2}$ adsorbed almost only cationic azo dyes, except for the anionic Quinizarin with an adsorption efficiency of 21.8\% [227, 228]. Apart from photooxidation, the photoreduction of azo dyes is also known as a significant decolorizing or a folding pathway. This fact can be explained in relation to the surface structure of $\mathrm{TiO}_{2}$. In the unmodified surface structure of crystal $\mathrm{TiO}_{2}$, oxygen atoms are mainly present with a high electron density which creates a negative center [228-230]. Thus, the $\mathrm{TiO}_{2}$ particles have a negative charge and are more suitable to adsorb cationic azo dyes than the ones with anionic characteristics [182, 231, 232]. Furthermore, the modelling of photodecoloration of nonbiodegradable azo dyes was investigated recently with Reactive Red 2 in a cocktail mixture of triethylamine and acetone. It was found that the cocktail photolysis system was able to entirely decolorize the azo dye in a short time and the overall dye removal followed pseudofirst-order decay kinetics [233].

Furthermore, a $\mathrm{TiO}_{2}$-based photocatalysis for azo dye degradation has been developed. It can be applied as a film and has the effectiveness of the slurry [234-236]. An approach to enhance the photocatalytic reaction rate is by modifying the semiconductor with transition metal. Decorating $\mathrm{TiO}_{2}$ with other metal/nonmetal or metal/metal combinations can decrease its band gap and allow for activation by the longer wavelength of visible light [237-239]. Hence, solar energy can be used more effectively in the photocatalysis process. Currently, many metals (e.g., Fe, Cu, Co, Al, Cr, $\mathrm{Ce}, \mathrm{Ag}$, and $\mathrm{Nd}$ ) and nonmetals (N, C, F, S, and B) have been attached onto $\mathrm{TiO}_{2}$ for azo dye degradation [237-242]. Among the metals, $\mathrm{Ag}^{+}$has been recognized to be more effective than $\mathrm{Fe}^{3+}, \mathrm{Co}^{2+}, \mathrm{Ce}^{4+}$, and $\mathrm{Cu}^{2+}$, since it traps the photogenerated electrons and avoids the recombination of electrons and holes [243].

$\mathrm{ZnO}$ has been demonstrated to have a much higher efficiency than $\mathrm{TiO}_{2}$ in the case of azo dyes degradation irradiated by UV light; however, studies on heterojunction systems applied to water treatment have primarily been restricted to the sensitization of $\mathrm{TiO}_{2}[244,245]$. This statement has been supported by the fact that $\mathrm{ZnO}$ has numerous advantages over $\mathrm{TiO}_{2}$. This includes high efficient photocatalytic activity, and photodegradation of diluted azo dyes cannot proceed sufficiently because of insufficient contact between azo dyes and semiconductors. This is an important factor in hindering photocatalytic activity [246]. The mass transfer from azo dyes to the semiconductor surface limits the photodegradation rate of diluted azo dyes. It is important that visible light degradation of some dyes utilizing $\mathrm{ZnO}$ was shown to be more effective than $\mathrm{TiO}_{2}$. In this case the 

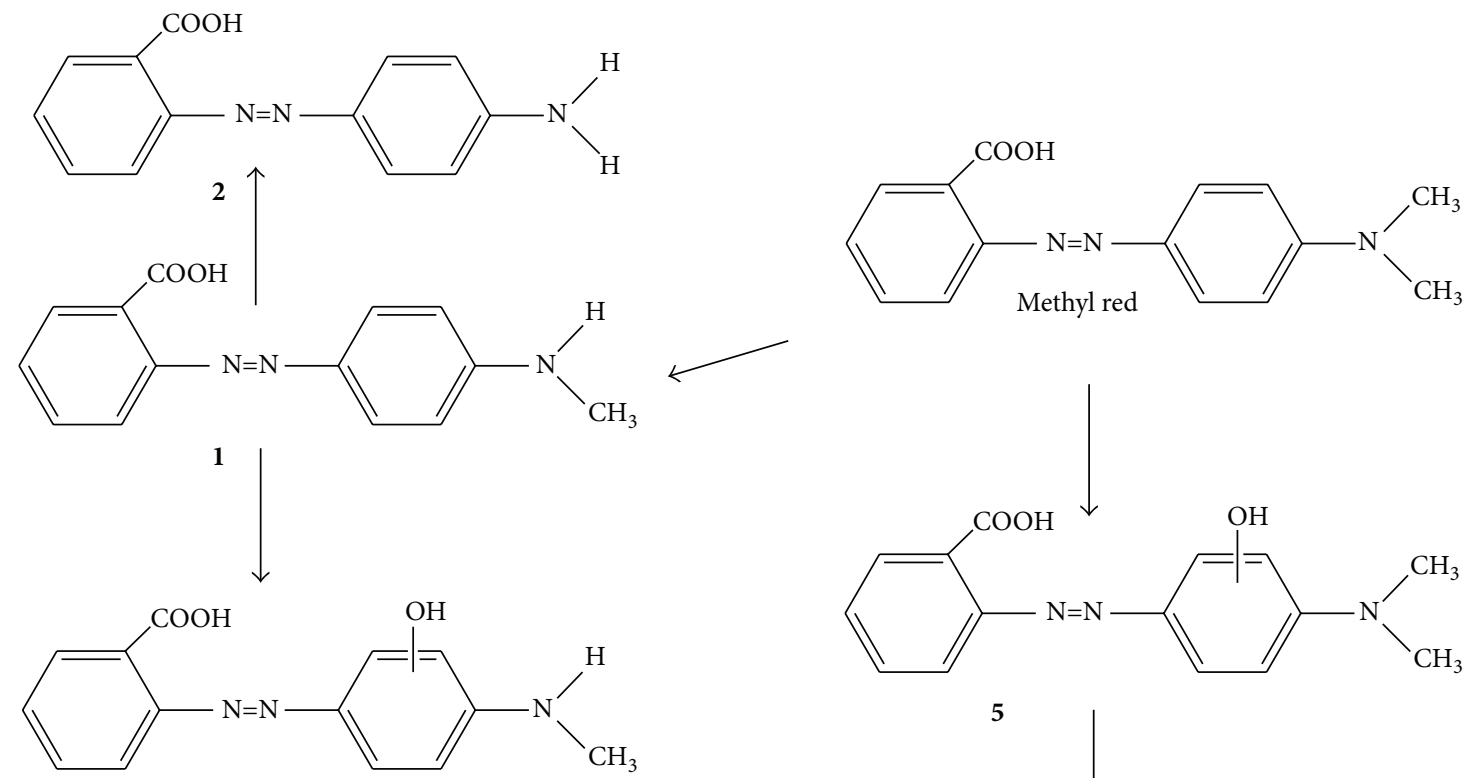

3

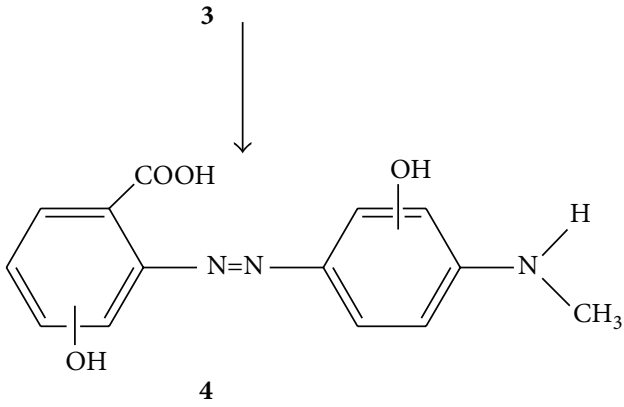

Ring opening

FIGURE 6: Proposed pathway for the photodecolorization of methyl red [216].

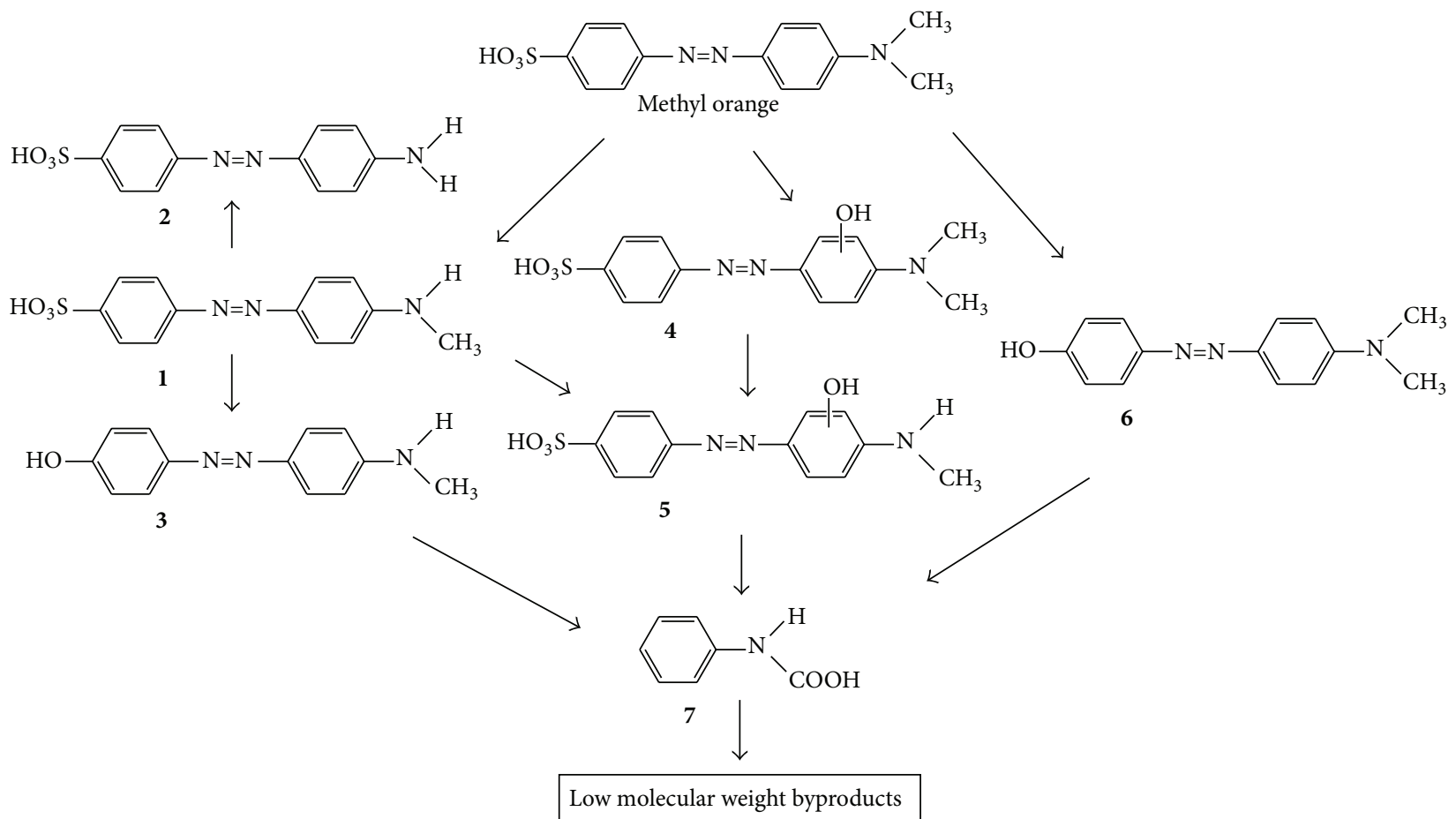

FIGURE 7: Proposed pathway for the photodecolorization degradation of methyl orange [216]. 
degradation mechanism was based on electron injection from the exited dyes to the $\mathrm{ZnO}$ conduction band. This was much more significant as compared to $\mathrm{TiO}_{2}$ which indicates high efficiency of charge transport and limited charge loss [247249].

\subsection{Photocatalytic Decolorization of Sulfur Dyes. Textile} industries generate large amounts of colored sulfur dye effluents which are toxic and induce a lot of damage to the environment. In view of the mutagenic character or carcinogenic nature of sulfur dyes, the deleterious effects of the color in receiving water, and the customary resistance of the sulfur dyes to biological degradation, the necessity of investigating new alternatives for appropriate treatment of this kind of dyes is evident [250-252]. Thus, various methods for the removal of sulfur dyes have been reported, including biological and chemical flocculation, coagulation, adsorption and oxidation, electrochemical oxidation, membrane separation, and ion exchange methods [253-255]. These methods have their own limitations for the removal of sulfur dyes, including being expensive, time consuming, and commercially unattractive as well as resulting in the production of secondary wastes [254]. Furthermore, these processes are also ineffective for sulfur dye removal since sulfur dyestuff is biorecalcitrant. In addition, these series of physicochemical treatments prepare only a phase transfer of sulfur dyes and produce huge quantities of sludge [256, 257].

The efficiency of a photocatalytic decolorization reaction is determined by the properties and quality of the photocatalyst, which is often a semiconductor with the ability to create electron-hole pairs under photoillumination [258, 259]. Thus, it is an important step to recognize an efficient and suitable photocatalyst during the decomposition process. In recent decades, different mixed metal oxides consisting of $\mathrm{TiO}_{6}$, $\mathrm{TaO}_{6}$, or $\mathrm{NbO}_{6}$ octahedral units, such as $\mathrm{BaTi}_{4} \mathrm{O}_{9}, \mathrm{SrTiO}_{3}$, $\mathrm{K}_{4} \mathrm{Nb}_{6} \mathrm{O}_{17}, \mathrm{InTaO}_{4}$, and $\mathrm{Ni}_{x} \mathrm{TaO}_{4}$ had been extensively investigated as a new class of photocatalysts in the field of sulfur dye degradation [260-262]. These kinds of photocatalysts belong to a family of uniform heterogenous catalysts [261]. Yet only a few of these photocatalysts have been studied for the removal of environmental contaminants, and earlier authors have all used the solid-solid blending method to synthesize their sample. Recently, the typical photocatalysts developed are mostly oxides containing d-block element ions as $\mathrm{Ti}^{4+}, \mathrm{Ta}^{5+}, \mathrm{Nb}^{5+}$, and $\mathrm{Zr}^{4+}$ with $\mathrm{d} 0$ electron configuration [263]. Very recently, researches have also focused on p-block metal oxide photocatalyst with d10 electron configuration due to their fair mobility for sulfur dye degradation $[261,262]$. $\mathrm{TiO}_{2}$ was found to be the most efficient photocatalyst for photodegradation of sulfur dyes because of faster electron transfer of molecular oxygen [264-266]. Furthermore, $\mathrm{TiO}_{2}$ photocatalyst is largely available as a nontoxic, inexpensive, and with relatively high chemical stability [42]. It has been noted that the photocatalytic degradation of sulfur dyes in solution is initiated by photoexcitation of the semiconductor, followed by formation of an electron-hole pair on the semiconductor surface [267]. The high oxidation potential of the hole in the semiconductor permits the direct oxidation of sulfur dyes into reactive intermediates [268, 269]. Highly reactive $\mathrm{OH}^{\circ}$ can also be formed either by decomposition of water or by the reaction of the hole with $\mathrm{OH}^{-}$. The $\mathrm{OH}^{\bullet}$ radical is a very strong, nonselective oxidant that leads to the degradation of organic chemicals [270].

There are certain relationships between properties of dyes and treatment mechanisms. Sulfur dyes are often made of azo compounds, sulfide structures, or anthraquinones, and they have several $-\mathrm{C}=\mathrm{O},-\mathrm{NH}-$, and aromatic groups. These dyes tend to be adsorbed by $\mathrm{Fe}(\mathrm{OH})_{x}$ particles [271273]. However, the photodegradation of sulfur dyes utilizing semiconductors is not new. The sulfur dye treatment of photocatalyst would be more suitable if the semiconductor was immobilized, so the semiconductors would not have to be separated from the sulfur dye solution [274, 275]. Thin films are one of the most important technological applications. Thin film photocatalyst towards sulfur dyes photodegradation offers high stability and convenient reuse and hence has received more and more attention [276]. Furthermore, photocatalysis supports such as zeolite have been extensively used to enhance the photodegradation of sulfur dyes. Zeolites are crystalline aluminosilicates with cavities in which the size can change in the range from one to several tens of nanometers depending on the type of aluminosilicate framework, $\mathrm{Al} / \mathrm{Si}$ ratio, and the origin of the ion exchange cations [277-279]. These characteristics of zeolite make it more selective for photocatalytic oxidation and are crucial especially when using environmentally benign oxidants.

\section{Recent Advances in Synthetic Dyes Photocatalytic Decolorization}

Industrial effluent detoxification is one of the most challenging global problems. Dyes, phenols, pesticides, fertilizers, detergents, herbicides, surfactants, and other synthetic organic compounds are disposed of directly into the environment, without being treated, controlled, or uncontrolled, without an effective treatment strategy [280-282]. Their toxicity, stability to natural decomposition, and persistence in the environment have been the cause of much concern to societies and regulatory authorities around the world [283, 284].

Although the strong potential of photocatalytic process for wastewater treatment is widely recognized via numerous patents and publications, technical development at industrial level has not been met with much success [285-287]. This is due to the high operating cost of the photocatalytic oxidation process relative to existing biological treatments [288]. Since in tropical countries, sunshine is available in abundance; therefore, application of this oxidation technology using solar light can be a cost- and energy-effective detoxification technology. Furthermore, the limitations of the photocatalyst system can be addressed in terms of the tight range of $\mathrm{pH}$ in which the reaction proceeds, the requirement for recovering the precipitated catalyst after treatment, and the deactivation by some ion-complexing agents such as phosphate anions $[289,290]$. 
Using solar energy is an interesting aspect in photocatalyst technologies. Solar photocatalysis has become an important area of research in which sunlight is the source of illumination to perform various photocatalytic reactions with regard to different kinds of dyes [291, 292]. As visible light is the main component of solar radiation, the development of a stable photocatalytic system, which can be affected by visible light, is most probably indispensable. In order to overcome the limitations, many studies on coupled semiconductor photocatalysts like $\mathrm{ZnO}-\mathrm{TiO}_{2}, \mathrm{CuO}-\mathrm{ZnO}$, $\mathrm{CuO}-\mathrm{TiO}_{2}, \mathrm{CuO}-\mathrm{SnO}_{2}, \mathrm{TiO}_{2}-\mathrm{SnO}_{2}, \mathrm{ZnO}-\mathrm{SnO}_{2}$, and so on have been reported [198, 293-295]. These series of binary oxide photocatalysts showed enhanced catalytic activities and selectivities compared to the monocomponent photocatalyst. This combined system also provides a more controllable rate of recombination as the composition of two semiconductors with different band gaps can suppress the recombination of $\mathrm{e}^{-} / \mathrm{h}^{+}$pairs [296]. Amongst the series of binary systems, $\mathrm{CdS} / \mathrm{TiO}_{2}$ showed the most prospect as an effective visible light photocatalyst for dye reduction and degradation. In the system of $\mathrm{TiO}_{2} / \mathrm{CdS}$, the photogenerated electrons in CdS are transferred into the $\mathrm{TiO}_{2}$ particle, while the holes remain in the CdS particles [297, 298]. This combination has also overcome the limitation of native CdS as photocatalyst due to its photocorrosion. Other researchers have loaded semiconductor with carbon-based nanomaterials like activated carbon, CNTs, graphene, graphite, and other matrices to improve the photocatalytic activity or cycling and its ratings performance [299-302]. Meanwhile, recent research has indicated that organic polymer films such as chitosan and cellulose films can ensure the stabilization of semiconductors especially in nanosized form and also provide an interface for the charge transfer and correspondingly improve photocatalytic efficiency [301-303]. In addition, the incorporation of such biopolymers assist in reducing the leakage of semiconductor particles in treated water during the dye removal and degradation, since those types of biopolymers are effective adsorbents and chelators for semiconductor ions in aqueous solutions [304].

\section{Influence of Dye Type on the Photocatalytic Process}

The chemical structure of the organic dyes has a considerable effect on the reactivity of dyes on photodegradation system [301]. This effect has been explored by different researchers. For example, the COD removal rate of RY17 was found to be higher than RR2 and RB4 dyes. This is due to the structural difference among the three molecules of dyes. RY17 and RR2 are equipped with an azo group $(-\mathrm{N}=\mathrm{N}-$ ), which is not present in RB4 molecules and suspected to photodegradation. In addition, $-\mathrm{CH}_{2}-\mathrm{OS}_{2}-$ linkage in RY17 is also labile in the reaction environment. In RB4, the presence of anthraquinone structure and the absence of azo band make it resistant to photodegradation [305].

Meanwhile, the removal of reactive orange 16 was maximum, closely followed by reactive blue 4 and reactive 5 in case of $\mathrm{TiO}_{2}$ photocatalysis. It may be due to the difference in chemical structure of dyes, resulting in difference in adsorption characteristics and difference in susceptibility to photodegradation $[43,44,47]$. The chemical structure of the dyes indicates that reactive black 5 has more complex structure, making it less photodegradable. Another reason may be due to absorption of light photon by dye itself leading to a less availability of photons for hydroxyl radical generation. It was observed from the absorption spectra of three dyes in near UV range that reactive black 5 strongly absorbs near UV radiation compared to reactive orange 16 and reactive blue 4 , leading to less by the dye molecules is thought to have an inhibitory effect on the photogeneration of holes or hydroxyl radicals, because of the lack of any direct contact between the photons and immobilized $\mathrm{TiO}_{2}$. [48]. Indeed, it causes the dye molecules to adsorb light and the photons never reach the photocatalyst surface; thus, the photodegradation efficiency decreases.

It is also important to notice that degradation pathway of organic dyes may be different as according to the chemical structure and functional groups. For example, with an addition of a ${ }^{\circ} \mathrm{OH}$ radical to an aromatic ring of dyes molecules, a labile $\mathrm{H}$ atom is produced [56-60]. This mechanism is also unsatisfactory for hydroxy azo dyes (AO7 and $\mathrm{AO} 8)$. In that case, abstraction of the $\mathrm{H}$ atom, carried by an oxygen atom in the azo form and by a nitrogen atom in the hydrazone form, competes with the addition of ${ }^{\circ} \mathrm{OH}$ radical on a phenyl or naphthyl nucleus [72].

The functional groups in the chemical structure of dye could be nitrite groups, alkyl side chain, chloro group, carboxylic group, sulfonic substituent, and also hydroxyl groups [305]. The appropriate photocatalyst material has to be chosen depending on these functional groups in the chemical structure of dye [81-84]. Every group that tends to decrease the solubility of molecules in water will decrease the degradation process. In order to evaluate the influence of a nitrite group, the degradation of an analogous pair of dyes such as Acid Red 29 and Chromotrope 2B can be mentioned. Chromotrope $2 \mathrm{~B}$ contains a nitrite group in the para position with respect to the azo function [305]. This substituent interacts with the phenyl ring and there is a consequent delocalization of the $\mathrm{p}$ electrons of the ring and of the unpaired electrons of the heteroatom. As a result, the phenyl ring is electron-enriched, and the nitrite group thus favors attack of an electrophilic entity. The experiment confirms this hypothesis: Chromotrope $2 \mathrm{~B}$ reaction rate is slightly higher than that of AR29. Hydroxyl radicals have a very short lifetime, so that they can only react where they are formed [72]. Therefore, oxidation reactions can only be successfully performed in homogeneous media. As it was previously mentioned, every group that tends to decrease the solubility of molecules in water will decrease the degradation process. This explains why the rate of decomposition clearly decreases with increasing length of the side chain and consequently with increasing hydrophobicity of the dye molecule, as seen at the degradation of AB25 and RB19 [81-85]. A parallel reaction may take place between ${ }^{\circ} \mathrm{OH}$ radical and hydrogen atoms of the side chains. This reaction competes with destruction of the dye chromophore, without leading to a decrease in the absorbance of the solution. 
Considerable decrease of photocatalytic decolorization rate was observed when two or three chloro substituents were present on the phenyl ring of a pyrazolone dye [104, 170]. Indeed, comparison of acid yellow 17 and acid yellow 23 decolorization rates suggests that the difficulty of the dye to be degraded directly depends on the number of electron withdrawing chloro groups in the molecule. The decolorization kinetics of acid yellow 17 is less than those of acid yellow 23 .

The photocatalytic decolorization of four organic dyessuch as Alizarin S, Orange G, Methyl Red, and Congo Red by $\mathrm{UV} / \mathrm{TiO}_{2}$ has been processed to explore the effect of the presence of carboxylic substituent in dye chemical structure. The photocatalytic rate constants were in the following order: Methyl Red > Orange $\mathrm{G} \approx$ Alizarin $\mathrm{S}>$ Congo Red [274]. It has been explained that the higher degradability of MR could be due to the presence of a carboxylic group which can easily react with $\mathrm{H}^{+}$via a photoKolbe reaction. However, the presence of a withdrawing group such as $-\mathrm{SO}_{3}{ }^{-}$is probably at the origin of the less efficient Orange $G$ and Alizarin S degradations [274]. Another suggestion to explain the different reactivity of these dyes could also be their ability to adsorb on $\mathrm{TiO}_{2}$ surface.

Unexpectedly, the presence of the more powerful electron withdrawing sulfonic group on a molecule makes it only very slightly less sensitive to oxidation. Indeed, molecules with one, two, or three sulfonic functions have almost the same reactivity with respect to oxidation by hydroxyl radicals $[63,83,169,209]$. Acid red 14 containing two sulfonic groups is more reactive in a photocatalytic degradation process in comparison with acid red 18 and acid red 27 that contain three sulfonic substituents [169]. Study of the influence of the sulfonic group is very difficult, because this substituent operates in different fields: it decreases electron density in the aromatic rings and the $\beta$ nitrogen atom of the azo bond by $-\mathrm{I}$ and $+\mathrm{M}$ effects. On the other hand, it increases the hydrophilic-lipophilic balance of the dye molecules and consequently slows down their aggregation degree $[63,209]$.

The electronic properties of a hydroxyl group are -I and $+\mathrm{M}$ effects. That is why the photocatalytic decolorization rate of acid red 29, which contains two hydroxyl substituents, is more than that of orange $G$, which contains one hydroxyl substituent [83]. In both dyes, one molecule contains a hydroxyl group next to the azo bond. But the resonance effect of a substituent operates only when the group is directly connected to the unsaturated system. Therefore, to explain the effect of the hydroxyl group on the reactivity of the organic matter, only the field effect (-I) must be considered. The number of hydroxyl groups in the dye molecule can intensify this resonance and, consequently, the degradation rate of the dye [209].

Photocatalytic decolorization rate of monoazo dyes is higher than dyes with anthraquinone structure. The presence of methyl and chloro groups in the dye molecule decreases slightly the process efficiency while a nitrite group acts in an opposite direction [305]. Alkyl side chain decreases the solubility of molecule in water and consequently disfavors the photocatalytic degradation process. The dyes which contain more sulfonic substituents are less reactive in the photocatalytic process, while hydroxyl group intensifies the electron resonance in the molecule and the degradation rate of the dye. Photocatalytic decolorization takes place at the surface of the catalyst. Dye molecules adsorb onto the surface of photocatalyst material by electrostatic attraction and get mineralized by nonselective hydroxyl radicals. Therefore, the adsorption of the target molecule on photocatalyst material surface may be regarded as a critical step toward efficient photocatalysis.

\section{Conclusion}

In the textile industry, regulations concerning the discharge of wastewater have become more and more stringent. The synthetic dyes utilized in the textile and other industries generate hazardous waste. The dye is utilized to impart color to materials of which it becomes an integral part. However, dye removal is an important but challenging area of wastewater treatment since some dyes and their degradation products are carcinogenic and toxic to mammals. Destructive oxidation of poisonous dyes via photocatalytic approaches have recently received considerable attention since colored aromatic compounds have proven to be degraded effectively by a variety of heterogenous semiconductor catalysts. Photocatalysis aims at mineralization of poisonous dyes to $\mathrm{CO}_{2}$, $\mathrm{H}_{2} \mathrm{O}$ and inorganic compounds or at least their transformation into biodegradable or harmless products. Finally, taking into account that UV light is not only expensive but also harmful to aquatic life, there is the need to improve the ability of photocatalysts to work with visible light.

\section{Conflict of Interests}

The authors declare that there is no conflict of interests regarding the publication of this paper.

\section{Acknowledgments}

This work is financially supported by University Malaya Research Grant (UMRG RP022-2012E) and Fundamental Research Grant Scheme (FRGS: FP049-2013B) by Universiti Malaya and Ministry of High Education, Malaysia, respectively.

\section{References}

[1] W. Zhang and C. W. Wu, "Dyeing of multiple types of fabrics with a single reactive azo disperse dye," Chem Papers, vol. 68, pp. 330-335, 2014.

[2] S. Nagai, "Induction of the respiration-deficient mutation in yeast by various synthetic dyes," Science, vol. 130, no. 3383, pp. 1188-1189, 1959.

[3] A. Heinfling, M. J. Martinez, A. T. Martinez, M. Bergbauer, and U. Szewzyk, "Transformation of industrial dyes by manganese peroxidases from Bjerkandera adusta and Pleurotus eryngii in a manganese-independent reaction," Applied and Environmental Microbiology, vol. 64, no. 8, pp. 2788-2793, 1998. 
[4] Y.-C. Hsiao, T.-F. Wu, Y.-S. Wang, C.-C. Hu, and C. Huang, "Evaluating the sentizing effect on the photocatalytic degradation of fyes using anatase-TiO, ${ }_{2}$, Applied Catalysis B, vol. 148, pp. 250-257, 2014.

[5] S. Zhang, "Preparation of controlled shape Zn S microcrystals and photocatalytic property," Ceramics International, vol. 40, pp. 4553-4557, 2014.

[6] A. Cavaco-Paulo, J. Morgado, L. Almeida, and D. Kilburn, "Indigo backstaining during cellulase washing," Textile Research Journal, vol. 68, no. 6, pp. 398-401, 1998.

[7] H. Duffner, E. Bach, E. Cleve, and E. Schollmeyer, "New mathematical model for determining time-dependent adsorption and diffusion of dyes into fibers through dye sorption curves in combination shades. Part II: kinetic data from dyeing cotton with a trichrome direct dye system," Textile Research Journal, vol. 70, no. 3, pp. 223-229, 2000.

[8] T. Bechtold and A. Turcanu, "Electrochemical vat dyeing combination of an electrolyzer with a dyeing apparatus," Journal of the Electrochemical Society, vol. 149, no. 1, pp. D7-D14, 2002.

[9] H. E. Liang, S. Zhang, B. Tang, L. Wang, and J. Yang, "Dyeability of polylactide fabric with hydrophobic anthraquinone dyes," Chinese Journal of Chemical Engineering, vol. 17, no. 1, pp. 156159, 2009.

[10] S. R. Marder, C. B. Gorman, F. Meyers et al., "A unified description of linear and nonlinear polarization in organic polymethine dyes," Science, vol. 265, no. 5172, pp. 632-635, 1994.

[11] C. S. Tidball, "Intestinal and hepatic transport of cholate and organic dyes," The American Journal of Physiology, vol. 206, pp. 239-242, 1964.

[12] W. Tanthapanichakoon, P. Ariyadejwanich, P. Japthong, K. Nakagawa, S. R. Mukai, and H. Tamon, "Adsorption-desorption characteristics of phenol and reactive dyes from aqueous solution on mesoporous activated carbon prepared from waste tires," Water Research, vol. 39, no. 7, pp. 1347-1353, 2005.

[13] O. Greengauz-Roberts, H. Stoppler, S. Nomura et al., "Saturation labeling with cysteine-reactive cyanine fluorescent dyes provides increased sensitivity for protein expression profiling of laser-microdissected clinical specimens," Proteomics, vol. 5, no. 7, pp. 1746-1757, 2005.

[14] M. Casetta, V. Koncar, and C. Caze, "Mathematical and modeling of the diffusion coefficient for disperse dyes," Textile Research Journal, vol. 71, no. 4, pp. 357-361, 2001.

[15] K. Ryberg, B. Gruvberger, E. Zimerson et al., "Chemical investigations of disperse dyes in patch test preparations," Contact Dermatitis, vol. 58, no. 4, pp. 199-209, 2008.

[16] P. Lebaron, N. Parthuisot, and P. Catala, "Comparison of blue nuclei acid dyes for flow cytometric enumeration of bacteria in aquatic systems," Applied and Environmental Microbiology, vol. 64, no. 5, pp. 1725-1730, 1998.

[17] N. Daneshvar, D. Salari, and A. R. Khataee, "Photocatalytic degrdataion of azo dye acid red 14 in water on azo as an alternative catalyst of $\mathrm{TiO}_{2}$," Journal of Photochemistry and Photobiology A, vol. 162, no. 2-3, pp. 317-322, 2004.

[18] R. Russ, J. Rau, and A. Stolz, "The function of cytoplasmic flavin reductases in the reduction of azo dyes by bacteria," Applied and Environmental Microbiology, vol. 66, no. 4, pp. 1429-1434, 2000.

[19] H. Xu, T. M. Heinze, S. Chen, C. E. Cerniglia, and H. Chen, "Anaerobic metabolism of 1-amino-2-naphthol-based azo dyes (Sudan dyes) by human intestinal microflora," Applied and Environmental Microbiology, vol. 73, no. 23, pp. 7759-7762, 2007.
[20] R. R. Peterson and J. Weiss, "Staining of the adenohypophysis with acid and basic dyes," Endocrinology, vol. 57, no. 1, pp. 96108, 1955.

[21] L. Peters, K. J. Fenton, M. L. Wolf, and A. Kandel, "Inhibition of the renal tubular excretion of $\mathrm{N}^{\prime}$-methylnicotinamide (NMN) by small doses of a basic cyanne dye," The Journal of Pharmacology, vol. 113, no. 2, pp. 148-159, 1955.

[22] M. Wang, N. Chamberland, L. Breau et al., "An organic redox electrolyte to rival triiodide/iodide in dye-sensitized solar cells," Nature Chemistry, vol. 2, no. 5, pp. 385-389, 2010.

[23] L. Camarero, R. Peche, J. M. Merino, and E. Rodríguez, "Photoassisted oxidation of indigocarmine in an acid medium," Environmental Engineering Science, vol. 20, no. 4, pp. 281-287, 2003.

[24] S. Blumel, M. Contzen, M. Lutz, A. Stolz, and H.-J. Knackmuss, "Isolation of a bacterial strain with the ability to utilize the sulfonated azo compound 4-carboxy- $4^{\prime}$-sulfoazobenzene as the sole source of carbon and energy," Applied and Environmental Microbiology, vol. 64, no. 6, pp. 2315-2317, 1998.

[25] Y. Hong, M. Xu, J. Guo, Z. Xu, X. Chen, and G. Sun, "Respiration and growth of Shewanella decolorationis S12 with an azo compound as the sole electron acceptor," Applied and Environmental Microbiology, vol. 73, no. 1, pp. 64-72, 2007.

[26] A. Sharma, S. Rani, A. Bansal, and A. Sood, "Effect of mordant combination on silk dyeing with apricot dye," in Natural Dyes: Scope and Challenges, pp. 137-143, Scientific Publishers, 2006.

[27] K. Harbinder and K. Namrita, "Eco-friendly finishing and dyeing of jute with direct and mordant dye method," Asian Journal of Home Science, vol. 7, pp. 19-22, 2012.

[28] G. R. Cameron and G. Scholar, "The staining of calcium," The Journal of Pathology and Bacteriology, vol. 33, pp. 929-955, 2005.

[29] N. Panchuk-Voloshina, R. P. Haugland, J. Bishop-Stewart et al., "Alexa dyes, a series of new fluorescent dyes that yield exceptionally bright, photostable conjugates," Journal of Histochemistry and Cytochemistry, vol. 47, no. 9, pp. 1179-1188, 1999.

[30] A. Mathur, Y. Hong, B. K. Kemp, A. A. Barrientos, and J. D. Erusalimsky, "Evaluation of fluorescent dyes for the detection of mitochondrial membrane potential changes in cultured cardiomyocytes," Cardiovascular Research, vol. 46, no. 1, pp. 126-138, 2000.

[31] H. H. Szeto, P. W. Schiller, K. Zhao, and G. Luo, "Fluorescent dyes alter intracellular targeting and function of cellpenetrating tetrapeptides," The FASEB Journal, vol. 19, no. 1, pp. 118-120, 2005.

[32] D. A. Hinckley, P. G. Seybold, and D. P. Borris, "Solvatochromism and thermochromism of rhodamine solutions," Spectrochimica Acta Part A, vol. 42, no. 6, pp. 747-754, 1986.

[33] F. H. Hussein, "Chemical properties of treated textile dyeing wastewater," Asian Journal of Chemistry, vol. 25, pp. 9393-9400, 2013.

[34] L. He, H. S. Freeman, L. Lu, and S. Zhang, "Spectroscopic study of anthraquinone dye/amphiphile systems in binary aqueous/organic solvent mixtures," Dyes \& Pigments, vol. 91, no. 3, pp. 389-395, 2011.

[35] I. Yumoto, K. Hirota, Y. Nodasaka, Y. Yokota, T. Hoshino, and K. Nakajima, "Alkalibacterium psychrotolerans sp. nov., a psychrotolerant obligate alkaliphile that reduces an indigo dye," International Journal of Systematic and Evolutionary Microbiology, vol. 54, no. 6, pp. 2379-2383, 2004.

[36] C. P. Raut, M. D. Daley, K. K. Hunt et al., "Anaphylactoid reactions to isosulfan blue dye during breast cancer lymphatic mapping in patients given preoperative prophylaxis," Journal of Clinical Oncology, vol. 22, no. 3, pp. 567-568, 2004. 
[37] Z.-F. Huang, J.-J. Zou, L. Pan, S. Wang, X. Zhang, and L. Wang, "Synergetic promotion on photoactivity and stability of $\mathrm{W}_{18} \mathrm{O}_{49} / \mathrm{TiO}_{2}$ hybrid," Applied Catalysis B, vol. 147, pp. 167-174, 2014.

[38] S. Sarkar and K. K. Chattopadhyay, "Visible light photocatalysis and electron emission from porous hollow spherical $\mathrm{BiVO}_{4}$ nanostructures synthesized by a novel route," Physica E, vol. 58, pp. 52-58, 2014.

[39] V. L. Blair, E. J. Nichols, J. Liu, and S. T. Misture, "Surface modification of nanosheet oxide photocatalysts," Applied Surface Science, vol. 268, pp. 410-415, 2013.

[40] Z. Li, Y. Shen, C. Yang et al., "Significant enchancement in the visible light pjotocatalytic properties of $\mathrm{BiFeO}_{3}$-graphene nanohybrids," Journal of Materials Chemistry A, vol. 1, pp. 823829, 2013.

[41] C. J. Miller, H. Yu, and T. Waite, "Degradation of rhodamine B during visible light photocatalysis employing Ag@ $\mathrm{AgCl}$ embedded on reduced graphene oxide," Colloids \& Surface A, vol. 435, pp. 147-153, 2013.

[42] S. Rashidi, M. Nikazar, A. V. Yazdi, and R. Fazaeli, "Optimized photocatalytic degradation of reactive blue 2 by $\mathrm{TiO}_{2} / \mathrm{UV}$ process," Journal of Environmental Science and Health, Part A, vol. 49, pp. 452-462, 2014.

[43] R.-H. Jie, G.-B. Guo, W.-G. Zhao, and S.-L. An, "Preparation and photocatalytic degradation of methyl orange of nano-powder $\mathrm{TiO}_{2}$ by hydrothermal method supported on activated carbon," Journal of Synthetic Crystals, vol. 42, pp. 2144-2149, 2013.

[44] Z. Bouberka, K. A. Benobbou, A. Khenifi, and U. Maschke, "Degradation by irradiation of an acid orange 7 on colloidal $\mathrm{TiO}_{2} /(\mathrm{LDHs})$," Journal of Photochemistry and Photobiology A, vol. 275, pp. 21-29, 2014.

[45] B. Pant, H. R. Pant, N. A. M. Barakat et al., "Incoporation of cadmium sulfide nanoparticles on the cadmium titanate nanofibers for enhanced organic dyes degradation and hydrogen release," Ceramics International, vol. 40, pp. 1553-1559, 2014.

[46] H. Hagiwara, M. Nagatomo, C. Seto, S. Ida, and T. Ishihara, "Dye-modification effects on water splitting activity of GaN:ZnO photocatalyst," Journal of Photochemistry and Photobiology A, vol. 272, pp. 41-48, 2013.

[47] A. Prasannan and T. Imae, "One-pot synthesis of fluorescent carbon dots from orange waste peels," Industrial \& Engineering Chemistry Research, vol. 52, pp. 15673-15678, 2013.

[48] L. G. Devi and M. L. Arunakumari, "Enhanced photocatalytic performance of Hemin (chloro(protoporhyinato) iron (III)) anchored $\mathrm{TiO}_{2}$ photocatalyst for methyl orange degradation: a surface modification method," Applied Surface Science, vol. 276, pp. 521-528, 2013.

[49] B. P. Nenavathu, A. V. R. Krishna Rao, A. Goyal, A. Kapoor, and R. K. Dutta, "Synthesis, characterization and enchanced photocatalytic degradation efficiency of Se doped $\mathrm{ZnO}$ nanoparticles using trypan blue as a model dye," Applied Catalysis A, vol. 459, pp. 106-113, 2013.

[50] Y. Huo, Z. Xie, X. Wang, H. Li, M. Hoang, and R. A. Caruso, "Methyl orange removal by combined visible-light photocatalysis and membrane distillation," Dyes \& Pigments, vol. 98, pp. 106-112, 2013.

[51] H. U. Lee, G. Lee, J. C. Park et al., "Efficient visible-light responsive $\mathrm{TiO}_{2}$ nanoparticles incoporated magnetic carbon photocatalysts," Chemical Engineering Journal, vol. 240, pp. 9198, 2014.

[52] S. O. Saheed, S. J. Modise, and A. M. Sipamla, “ $\mathrm{TiO}_{2}$ supported clinoptilotile: characterization and optimization of operational parameters for methyl orange removal," Advanced Materials Research, vol. 781, pp. 2249-2252, 2013.

[53] S. J. Hu, J. Yang, and X. H. Liao, "Highly efficient degradation of methylene blue on microwave synthesized $\mathrm{FeVO}_{4}$ nanoparticles photocatalyst under visible-light irradiation," Applied Mechanics and Materials, vol. 372, pp. 153-157, 2013.

[54] E. S. Aazam and R. M. Mohamed, "Environmental remediation of direct blue dyes solutions by photocatalytic oxidation with cuppor oxide," Journal of Alloys and Compounds, vol. 577, pp. 550-555, 2013.

[55] M. Xu, J. Guo, Y. Cen, X. Zhong, W. Cao, and G. Sun, "Shewanella decolorationis sp. nov., a dye-decolorizing bacterium isolated from activated sludge of a waste-water treatment plant," International Journal of Systematic and Evolutionary Microbiology, vol. 55, no. 1, pp. 363-368, 2005.

[56] E. Abadulla, T. Tzanov, S. Costa, K.-H. Robra, A. CavacoPaulo, and G. M. Gubitz, "Decolorization and detoxification of textile dyes with a laccase from Trametes hirsuta," Applied and Environmental Microbiology, vol. 66, no. 8, pp. 3357-3362, 2000.

[57] N. Sakkayawong, P. Thiravetyan, and W. Nakbanpote, "Adsorption mechanism of synthetic reactive dye wastewater by chitosan," Journal of Colloid and Interface Science, vol. 286, no. 1, pp. 36-42, 2005.

[58] Y. Wang, G. Wang, H. Wang, C. Liang, W. Cai, and L. Zhang, "Chemical-template synthesis of micro/nanoscale magnesium silicate hollow spheres for waste-water treatment," Chemistry: A European Journal, vol. 16, no. 11, pp. 3497-3503, 2010.

[59] J.-L. Gong, B. Wang, G.-M. Zeng et al., "Removal of cationic dyes from aqueous solution using magnetic multi-wall carbon nanotube nanocomposite as adsorbent," Journal of Hazardous Materials, vol. 164, no. 2-3, pp. 1517-1522, 2009.

[60] J. M. Peralta-Hernándeza, Y. Meas-Vong, F. J. Rodríguez, T. W. Chapman, M. I. Maldonado, and L. A. Godínez, "Comparison of hydrogen peroxide-based processes for treating dye-containing wastewater: decolorization and destruction of Orange II azo dye in dilute solution," Dyes \& Pigments, vol. 76, no. 3, pp. 656-662, 2008.

[61] B. N. Joshi, H. Yoon, S.-H. Na, J.-Y. Choi, and S. S. Yoon, "Enchanced photocatalytic performance of graphene- $\mathrm{ZnO}$ nanoplatet composite thin films prepared by electrostatic spray deposition," Ceramics International, vol. 40, pp. 3647-3654, 2014.

[62] M. Wang, J. Huang, Z. Tong, W. Li, and J. Chen, "Reduced graphene oxide-cuprous oxide composite via facial deposition for photocatalytic dye-degradation," Journal of Alloys and Compounds, vol. 568, pp. 26-35, 2013.

[63] U. G. Akpan and B. H. Hameed, "Development and photocatalytic activities of $\mathrm{TiO}_{2}$ doped with $\mathrm{Ca}-\mathrm{Ce}-\mathrm{W}$ in the degradation of acid red 1 under visible light irradiation," Desalination \& Water Treatment, 2013.

[64] S. Zhang, J. Li, M. Zeng et al., "In situ synthesis of watersoluble magnetic graphitic carbon nitride photocatalyst and its synergistic catalytic performance," ACS Applied Materials \& Interfaces, vol. 5, pp. 1235-1243, 2013.

[65] P. Peralta-Zamora, "Photoelectrochemical or electrophotochemical processes?" Journal of the Brazilian Chemical Society, vol. 21, no. 9, pp. 1621-1625, 2010.

[66] M. E. Olya and A. Pirkarami, "Cost-effective photoelectrocatalytic treatment of dyes in a batch reactor equipped with solar cells," Separation \& Purification Technology, vol. 118, pp. 557$566,2013$. 
[67] J. Ma, B. Cui, J. Dai, and D. Li, "Mechanism of adsorption of anionic dye from aqueous solutions onto organobentonite," Journal of Hazardous Materials, vol. 186, no. 2-3, pp. 1758-1765, 2011.

[68] M.-X. Zhu, L. Lee, H.-H. Wang, and Z. Wang, "Removal of an anionic dye by adsorption/precipitation processes using alkaline white mud," Journal of Hazardous Materials, vol. 149, no. 3, pp. 735-741, 2007.

[69] Y. Dong, W. Dong, C. Liu, Y. Chen, and J. Hua, "Photocatalytic decoloration of water-soluble azo dyes by reduction based on bisulfite-mediated borohydride," Catalysis Today, vol. 126, no. 3-4, pp. 456-462, 2007.

[70] A. Szyguła, E. Guibal, M. A. Palacín, M. Ruiz, and A. M. Sastre, "Removal of an anionic dye (Acid Blue 92) by coagulationflocculation using chitosan," Journal of Environmental Management, vol. 90, no. 10, pp. 2979-2986, 2009.

[71] M. A. M. Salleh, D. K. Mahmoud, W. A. W. A. Karim, and A. Idris, "Cationic and anionic dye adsorption by agricultural solid wastes: a comprehensive review," Desalination, vol. 280, no. 1-3, pp. 1-13, 2011.

[72] G. A. Ikhtiyarova, A. S. Özcan, O. Gök, and A. Özcan, "Characterization of natural- and organo-bentonite by XRD, SEM, FT-IR and thermal analysis techniques and its adsorption behaviour in aqueous solutions," Clay Minerals, vol. 47, pp. 3144, 2012.

[73] P. Baskaralingam, M. Pulikesi, D. Elango, V. Ramamurthi, and S. Sivanesan, "Adsorption of acid dye onto organobentonite," Journal of Hazardous Materials, vol. 128, no. 2-3, pp. 138-144, 2006.

[74] J. F. Ma, J. M. Yu, B. Y. Cui, D. L. Li, and J. Dai, “Treatment of dye wastewater by zero valent iron composited organobentonite," Advanced Materials Research, vol. 340, pp. 229-235, 2011.

[75] I. L. Lagadic, M. K. Mitchell, and B. D. Payne, "Highly effective adsorption of heavy metal ions by a thiol-functionalized magnesium phyllosilicate clay," Environmental Science and Technology, vol. 35, no. 5, pp. 984-990, 2001.

[76] F. Gao, P. Botella, A. Corma, J. Blesa, and L. Dong, "Monodispersed mesoporous silica nanoparticles with very large pores for enhanced adsorption and release of DNA," Journal of Physical Chemistry B, vol. 113, no. 6, pp. 1796-1804, 2009.

[77] X. Wang, R. Liu, M. M. Waje et al., "Sulfonated ordered mesoporous carbon as a stable and highly active protonic acid catalyst," Chemistry of Materials, vol. 19, no. 10, pp. 2395-2397, 2007.

[78] T. Suteewong, H. Sai, R. Cohen et al., "Highly aminated mesoporous silica nanoparticles with cubic pore structure," Journal of the American Chemical Society, vol. 133, no. 2, pp. 172$175,2011$.

[79] J. Tao, W. Jiang, H. Zhai, H. Pan, R. Xu, and R. Tang, "Structural components and anisotropic dissolution behaviors in one hexagonal single crystal of $\beta$-tricalcium phosphate," Crystal Growth and Design, vol. 8, no. 7, pp. 2227-2234, 2008.

[80] H. Pan, J. Tao, R. Xu, and R. Tang, "Adsorption processes of gly and glu amino acids on hydroxyapatite surfaces at the atomic level," Langmuir, vol. 23, no. 17, pp. 8972-8981, 2007.

[81] S. Rashmi and V. Preeti, "Decolorisation of aqueous dye solutions by low-cost adsorbents: a review," Coloration Technology, vol. 129, pp. 85-108, 2013.

[82] F. H. Hussein, "Effect of photocatalytic treatments on physical and biological properties of textile dyeing wastewater," Asian Journal of Chemistry, vol. 25, pp. 9387-9392, 2013.
[83] J. Moon, C. Y. Yun, K.-W. Chung, M.-S. Kang, and J. Yi, "Photocatalytic activation of $\mathrm{TiO}_{2}$ under visible light using Acid Red 44," Catalysis Today, vol. 87, no. 1-4, pp. 77-86, 2003.

[84] M. Y. Abdelaal and R. M. Mohamed, "Novel Pd/TiO ${ }_{2}$ nanocomposite prepared by modified sol-gel method for photocatalytic degradation of methylene blue dye under visible light irradation," Journal of Alloys and Compounds, vol. 576, pp. 201-207, 2013.

[85] M. G. Weinbauer, C. Beckmann, and M. G. Höfle, "Utility of green fluorescent nucleic acid dyes and aluminum oxide membrane filters for rapid epifluorescence enumeration of soil and sediment bacteria," Applied and Environmental Microbiology, vol. 64 , no. 12 , pp. 5000-5003, 1998 .

[86] A. Hamrouni, H. Lachheb, and A. Houas, "Synthesis, characterization and photocatalytic activity of $\mathrm{ZnO}-\mathrm{SnO}_{2}$ nanocomposites," Materials Science and Engineering B, vol. 178, pp. 1371-1379, 2013.

[87] H. G. Cha, H. S. Noh, M. J. Kang, and Y. S. Kang, "Photocatalysis: progress using manganese-doped hematite nanocrystals," New Journal of Chemistry, vol. 37, pp. 4004-4009, 2013.

[88] T. Jiang, L. Zhang, M. Ji et al., "Carbon nanotubes $/ \mathrm{TiO}_{2}$ nanotubes composite photocatalysts for efficient degrdation of methyl orange dye," Particuology, vol. 11, pp. 737-742, 2013.

[89] A. Fatemeh, F. Nazanin, and M. A. Tehrani Ramin, "Preparation of $\mathrm{NiO}$ loaded on $\mathrm{TiO}_{2}$ nanostructure as nanophotocatalyst and its photocatalytic activity for degradation of methylene blue," Research Journal of Chemistry and Environment, vol. 17, pp. 9296, 2013.

[90] F. A. Harraz, R. M. Mohamed, M. M. Rashad, Y. C. Wang, and W. Sigmund, "Magnetic nanocomposite based on titaniasilica/cobalt ferrite for photocatalytic degradation of methylene blue dye," Ceramics International, vol. 40, pp. 375-384, 2014.

[91] J. Zhang, W. Liu, X. Wang, X. Wang, B. Hu, and H. Liu, "Enchanced decolarization activity by $\mathrm{Cu}_{2} \mathrm{O} @ \mathrm{TiO}_{2}$ nanobelts heterostructures via a strong adsorption-weak photodegradation process," Applied Surface Science, vol. 282, pp. 84-91, 2013.

[92] M. Hamadanian, M. Behpour, A. S. Razavian, and V. Habbari, "Structural, morphological and photocatalytic characterisations of Ag-coated anatase $\mathrm{TiO}_{2}$ fabricated by the sol gel dip coating method," Journal of Experimental Nanoscience, vol. 8, pp. 901-912, 2013.

[93] B. Shahmoradi, A. Maleki, and K. Byrappa, "Removal of dispersed orange 25 using in situ surface iron-doped $\mathrm{TiO}_{2}$ nanoparticles," Desalination \& Water Treatment, 2013.

[94] Priyanka and V. C. Srivastava, "Photocatalytic oxidation of dye bearing wastewater by iron doped zinc-oxide," Industrial \& Engineering Chemistry Research, vol.52, no. 50, pp.17790-17799, 2013.

[95] L. Sun, Y. Shi, B. Li, X. Li, and Y. Wang, "Preparation and characterization of polypyyrole/ $\mathrm{TiO}_{2}$ nanocomposites by reverse microemulsion polymerization and its photocatalytic activity for the degradation of methyl orange under natural light," Polymer Composites, vol. 34, no. 7, pp. 1076-1080, 2013.

[96] B. Saygi and D. Tekin, "Photocatalytic degradation kinetics of reactive black 5 ( $\mathrm{RB} 5$ ) dyestuff on $\mathrm{TiO}_{2}$ modified by pretreatment with untrasound energy," Reaction Kinetics, Mechanisms and Catalysis, vol. 110, no. 1, pp. 251-258, 2013.

[97] C. C. Pei and W. W. F. Leung, "Photocatalytic degradation of Rhodamine $\mathrm{B}$ by $\mathrm{TiO}_{2} / \mathrm{ZnO}$ nanofibers under visible-light irradiation," Separation \& Purification Technology, vol. 114, pp. 108-116, 2013. 
[98] A. F. Shojaei, A. R. Tabari, and M. H. Loghmani, "Normal spinel $\mathrm{CoCr}_{2} \mathrm{O}_{4}$ and $\mathrm{CoCr}_{2} \mathrm{O}_{4} / \mathrm{TiO}_{2}$ nanocomposite as novel photocatalysts for degradation of dyes," Micro \& Nano Letters, vol. 8, pp. 426-431, 2013.

[99] J. B. Joo, I. Lee, M. Dahl, G. D. Moon, F. Zaera, and Y. Yin, "Controllable synthesis of mesoporous $\mathrm{TiO}_{2}$ hallows shells: toward an efficient photocatalyst," Advanced Functional Materials, vol. 23, pp. 4246-4254, 2013.

[100] L. Shi, L. Liang, J. Ma et al., "Highly efficient visible lightdriven $\mathrm{Ag} / \mathrm{AgBr} / \mathrm{ZnO}$ composite photocatalyst for degrading Rhodamine B," Ceramics International, vol. 40, pp. 3495-3502, 2014.

[101] B. M. Rajbongshi and S. K. samdarshi, " $\mathrm{ZnO}$ and $\mathrm{Co}-\mathrm{ZnO}$ nanorods-Complementary role of oxygen vacancy in photocatalytic activity of under UV and visible radiation flux," Materials Science and Engineering B, vol. 182, pp. 21-28, 2014.

[102] P. Muthirulan, C. K. Nirmala Devi, and M. M. Sundaram, "Facile synthesis of novel hierarchiral $\mathrm{TiO}_{2} @ P$ Poly $(\mathrm{o}-$ phenylenediamine) core-shell structures with enchanced photocatalytic performance under solar light," Journal of Environmental Chemical Engineering, vol. 1, pp. 620-627, 2013.

[103] W. Zhang, T. Hu, B. Yang, P. Sun, and H. He, "The effect of boron content on properties of $\mathrm{B}-\mathrm{TiO}_{2}$ photocatalyst prepared by solgel method," Journal of Advanced Oxidation Technologies, vol. 16, pp. 261-267, 2013.

[104] A. Mohamed, S. Alberto, M.-F. Victor, and E. Luis, "Removal of basic yellow cationic dye by an aqueous dispersion of Moroccan stevensite," Applied Clay Science, vol. 80, pp. 46-51, 2013.

[105] Z. D. Meng, L. Zhu, S. Ye et al., "Heterogenous photocatalytic degradation of anionic and cationic dyes over fefullerence/ $\mathrm{TiO}_{2}$ under visible light," Asian Journal of Chemistry, vol. 25, pp. 6001-6007, 2013.

[106] V. V. Panic and S. J. Velickovic, "Removal of model cationic dye by adsorption onto poly(methacrylic acid)/zeolite hydrogel composites: kinetics, equilibrium study and image analysis," Separation \& Purification Technology, vol. 122, pp. 284-294, 2014.

[107] Q. Li, Q.-Y. Yue, H.-J. Sun, Y. Su, and B.-Y. Gao, "A comparative study on the properties, mechanisms and process designs for the adsorption of non-ionic or anionic dyes onto cationicpolymer/bentonite," Journal of Environmental Management, vol. 91, no. 7, pp. 1601-1611, 2010.

[108] Y. Zhen, Y. Hu, J. Ziwen et al., "Flocculation of both anionic and cationic dyes in aqueous solutions by the amphoteric grafting flocculant carboxymethyl chitosan-graft-polyacrylamide," Journal of Hazardous Materials, vol. 254, pp. 36-45, 2013.

[109] A. Afkhami, M. Saber-Tehrani, and H. Bagheri, "Modified maghemite nanoparticles as an efficient adsorbent for removing some cationic dyes from aqueous solution," Desalination, vol. 263, no. 1-3, pp. 240-248, 2010.

[110] S. Iyyapushpam, S. T. Nishanti, and D. Pathinettam Padiyan, "Photocatalytic degradation of methyl orange using $\alpha-\mathrm{Bi}_{2} \mathrm{O}_{3}$ prepared without surfactant," Journal of Alloys and Compounds, vol. 563, pp. 104-107, 2013.

[111] S. K. Kansal, R. Lamba, S. K. Mehta, and A. Umar, "Photocatalytic degradation of Alizarin Red S using simply synthesized ZnO nanoparticles," Materials Letters, vol. 106, pp. 385-389, 2013.

[112] C. Zhu, Y. Li, Q. Su et al., "Electrospinning direct preparation of $\mathrm{SnO}_{2} / \mathrm{Fe}_{2} \mathrm{O}_{3}$ heterojunction nanotubes as an efficient visiblelight photocatalyst," Journal of Alloys and Compounds, vol. 575, pp. 333-338, 2013.
[113] S. Balachandran, S. G. Praveen, R. Velmurugan, and M. Swaminathan, "Facile fabrication of highly efficient, reusable heterostructured $\mathrm{Ag}-\mathrm{ZnO}-\mathrm{CdO}$ and its twin applications of dye degradation under natural sunlight and self-cleaning," $R S C$ Advances, vol. 4, pp. 4353-4362, 2014.

[114] H. Gulce, V. Eskizeybek, B. Haspulat, F. Sari, A. Gulce, and A. Avci, "Preparation of a new polyaniline/CdO nanocomposite and investigation of its photocatalytic activity: comparative study under UV light and natural sunlight irradation," Industrial \& Engineering Chemistry Research, vol. 52, pp. 1092410934, 2013.

[115] E. Repo, S. Rengaraj, S. Pulkka et al., "Photocatalytic degradation of dyes by CdS micropoheres under near UV and blue LED radiatin," Separation \& Purification Technology, vol. 120, pp. 206-214, 2013.

[116] N. Divya, A. Bansal, and A. K. Jana, "Nano-photocatalysts in the treatment of colored wastewater-a review," Materials Science Forum, vol. 734, pp. 349-363, 2013.

[117] D. Pathania, S. Sarita, and B. S. Rathore, "Synthesis, characterization and photocatalytic application of bovine serum albumin capped cadmium sulphide nanopartilces," Chalcogenide Letters, vol. 8, no. 6, pp. 396-404, 2011.

[118] A. Tadjorodi, M. Imani, and H. Kerdari, "Experimental design to optimize the synthesis of CdO cauliflower-like nanostructure and high performance in photodegaradtion of toxic azo dyes," Materials Research Bulletin, vol. 48, pp. 935-942, 2013.

[119] L. Bouna, B. Rhouta, and F. Maury, "Physicochemical study of photocatalytic activity of $\mathrm{TiO}_{2}$ supported polygorskite clay mineral," International Journal of Photoenergy, vol. 2013, Article ID 815473, 6 pages, 2013.

[120] Z.-L. Ma, G.-F. Huang, D.-S. Xu, M.-G. Xia, W.-Q. Huang, and Y. Tian, "Coupling effect of la doping and porphyrin sensitization on photocatalytic activity of nanocrystalline $\mathrm{TiO}_{2}$," Materials Letters, vol. 108, pp. 37-40, 2013.

[121] Z. Shi, M. Zhou, D. Zheng, H. Liu, and S. Yao, "Preparation of Ce-doped $\mathrm{TiO}_{2}$ hollow fibers and their photocatalytic degradation properties for dye compound," Journal of the Chinese Chemical Society, vol. 60, pp. 1156-1162, 2013.

[122] N. B. Gusiak, I. M. Kobasa, and S. S. Kurek, "Nature inspired dyes for the sensitization of titanium dioxide photocatalyst," Chemik, vol. 67, pp. 1191-1198, 2013.

[123] Y. Huo, X. Chen, J. Zhang, G. Pan, J. Jia, and H. Li, “Ordered macroporous $\mathrm{Bi}_{2} \mathrm{O}_{3} / \mathrm{TiO}_{2}$ film coated on a rotating disk with enchanced photocatalytic activity under visible irradiation," Applied Catalysis B, vol. 148, pp. 550-556, 2014.

[124] L.-J. Kim, J.-W. Jang, and J.-W. Park, "Nano $\mathrm{TiO}_{2}$ functionalized magnetic-cored dendrimer as a photocatalyst," Applied Catalysis B, vol. 147, pp. 973-979, 2014.

[125] J. Rattanarak, W. Mekprasart, W. Pecharapa, and W. Techitdheera, "Photocatalytic activities under UV light of ball-milled $\mathrm{TiO}_{2}$ photocatalyts," Advanced Materials Research, vol. 802, pp. 237-241, 2013.

[126] W. C. Liu, H. Y. Xu, T. N. Shi, L. C. Wu, and P. Li, "Preparation and photocatalytic activity of $\mathrm{TiO}_{2} /$ tourmaline composite catalyst," Advanced Materials Research, vol. 800, pp. 464-470, 2013.

[127] T. E. Agustina, F. S. Arsyad, and M. Abdullah, "Photocatalytic degradation of C.I reactive red 2 by using $\mathrm{TiO}_{2}$-coated PET plastic under solar irradiation," Advanced Materials Research, vol. 789, pp. 180-188, 2013.

[128] X. Sun, C. Li, L. Ruan et al., "Ce-doped $\mathrm{SiO}_{2} @ \mathrm{TiO}_{2}$ nanocomposite as an effective visible light photocatalyst," Journal of Alloys and Compounds, vol. 585, pp. 800-804, 2014. 
[129] M.-C. Wu, H.-C. Liao, Y.-C. Cho et al., "Photocatalytic activity of nitrogen-doped $\mathrm{TiO}_{2}$-based nanowires: a photo-assisted Kelvin probe force microcopy study," Journal of Nanoparticle Research, vol. 16, pp. 1-11, 2014.

[130] S. Shi, M. A. Gondal, A. A. Al-Saadi et al., "Facile preparation of $\mathrm{g}-\mathrm{C}_{3} \mathrm{~N}_{4}$ modified $\mathrm{BiOCl}$ hybrid photocatalyst and vital role of frontier orbital energy levels of model compounds in photoactivity enchecement," Journal of Colloid and Interface Science, vol. 416, pp. 212-219, 2014.

[131] A. E. Nogueira, E. Longo, E. R. Leite, and E. R. Camargo, "Synthesis and photocatalytic properties of bismuth titanate with different structures via oxidant peroxo method (OPM)," Journal of Colloid and Interface Science, vol. 415, pp. 89-94, 2014.

[132] Q. Wang, J. Hui, L. Yang et al., "Enchanced photoactivity performance of $\mathrm{Bi}_{2} \mathrm{O}_{3} / \mathrm{H}$-ZSM-5 composite for rgodamine $\mathrm{B}$ degradation under UV light irradiation," Applied Surface Science, vol. 289, pp. 224-229, 2014.

[133] Y. L. Ma, R. S. Xue, and H. S. Yan, "Photo-degaradtion alkali lignin by Bis-(2-Methyl Quinoline) squarylium cyanine $\mathrm{TiO}_{2}$ photocatalyst in sunlight," Advanced Materials Research, vol. 838, pp. 2717-2720, 2014.

[134] Q. Wang, J. Hui, Y. Huang et al., “The preparation of $\mathrm{BiOCl}$ photocatalyst and its performance of photodegradation on dyes," Materials Science in Semiconductor Processing, vol. 17, pp. 87-93, 2014.

[135] W. T. Yi and C. Y. Yan, "A novel visible-light-driven photocatalyst: Pt surface modofied $\mathrm{Bi}_{2} \mathrm{WO}_{6}-\mathrm{WO}_{3}$ composite," Applied Mechanics and Materials, vol. 448, pp. 178-181, 2014.

[136] Z. Liu, B. Wu, J. Niu, X. Huang, and Y. Zhu, "Solvothermal synthesis of BiOBr thin film and its photocatalytic performance," Applied Surface Science, vol. 288, pp. 369-372, 2014.

[137] Z. Li, S. Yang, J. Zhou et al., "Novel mesoporous g- $\mathrm{C}_{3} \mathrm{~N}_{4}$ and $\mathrm{BiPO}_{4}$ nanorods hybrid architectures and their enchanced visible-light-driven photocatalytic performances," Chemical Engineering Journal, vol. 241, pp. 344-351, 2014.

[138] M. Wang, Y. Che, C. Niu, M. Dang, and D. Dong, "Effective visible light-active boron and europium co-doped $\mathrm{BiVO}_{4}$ synthesized by sol-gel method for photodegradation of methyl orange," Journal of Hazardous Materials, vol. 262, pp. 447-455, 2013.

[139] G. Zhu, M. Hojamberdiev, K. I. Katsumata et al., "Heterostructured $\mathrm{Fe}_{3} \mathrm{O}_{4} / \mathrm{Bi}_{2} \mathrm{O}_{2} \mathrm{CO}_{3}$ photocatalyst: synthesis, characterization and application in recycleable photodegradation of organic dyes under visible light irradiation," Materials Chemistry and Physics, vol. 142, pp. 95-105, 2013.

[140] Q. Wang, J. Hui, J. Li et al., "Photodegradation of methyl orange with PANI-modified $\mathrm{BiOCl}$ photocatalyst under visble light irradiation," Applied Surface Science, vol. 283, pp. 577-583, 2013.

[141] Z. Zhanying, I. M. O'Hara, A. K. Geoff, and O. S. D. William, "Comparative study on adsorption of two cationic dyes by milled sugarcane bagasse," Industrial Crops and Products, vol. 42, pp. 41-49, 2013.

[142] S.-K. Mousa, A. Mokhtar, and G. Kamaladin, "Preparation of chitosan-ethyl acrylate as a biopolymer adsorbent for basic dyes removal from colored solutions," Journal of Environmental Chemical Engineering, vol. 1, pp. 406-415, 2013.

[143] K. Turhan, I. Durukan, S. A. Ozturkcan, and Z. Turgut, "Decolorization of textile basic dye in aqueous solution by ozone," Dyes \& Pigments, vol. 92, no. 3, pp. 897-901, 2012.

[144] A. T. Kah, M. Norhashimah, T. T. Tjoon, N. Ismail, and P. Panneerselvam, "Removal of cationic dye by magnetic nanoparticle $\left(\mathrm{Fe}_{3} \mathrm{O}_{4}\right)$ impregnated onto activated maize cob powder and kinetic study of dye waste adsorption," APCBEE Procedia, vol. 1, pp. 83-89, 2012.

[145] S. M. R. Billah, R. M. Christie, and R. Shamey, "Direct coloration of textiles with photochromic dyes. Part 1: application of spiroindolinonaphthoxazines as disperse dyes to polyester, nylon and acrylic fabrics," Coloration Technology, vol. 124, no. 4, pp. 223-228, 2008.

[146] M. M. Hassan and C. J. Hawkyard, "Decolourisation of aqueous dyes by sequential oxidation treatment with ozone and Fenton's reagent," Journal of Chemical Technology and Biotechnology, vol. 77, no. 7, pp. 834-841, 2002.

[147] B. Mralidharan and S. Laya, "A new approach to dyeing of $80: 20$ polyester/cotton blended fabric using disperse and reactive dyes," ISRN Materials Science, vol. 2011, Article ID 907493, 12 pages, 2011.

[148] H. Y. Ze, F. T. Jing, Q. W. Xiao, C. Xiu, L. Wei, and Z. Ying, "Effects of disperse dyes on dyeing of ethylated Chinese fir powder," Advanced Materials Research, vol. 788, pp. 241-245, 2013.

[149] W. Cui, H. Wang, L. Liu, Y. Liang, and J. G. McEvoy, "Plasmonic Ag@AgCl-intercalated $\mathrm{K}_{4} \mathrm{Nb}_{6} \mathrm{O}_{17}$ composite for enchanced photocatalytic degradation of Rhodamine B under visible light," Applied Surface Science, vol. 283, pp. 820-827, 2013.

[150] Z. Ali, N. R. Khalid, M. Nawaz Chaudhry, S. Tajammul Hussain, I. Ahamad, and N. A. Niaz, "Significant effect of graphene on catalytic degradation of methylene blue by pure and $\mathrm{Ce}$ doped $\mathrm{TiO}_{2}$ at nanoscale," Digest Journal of Nanomaterials and Biostructures, vol. 8, pp. 1525-1534, 2013.

[151] Q. Wang, J. Li, Y. Bai et al., "Photodegradation of textile dye Rhodamine B over a novel biopolymer-metal complex wool$\mathrm{Pd} / \mathrm{CdS}$ photocatalysts under visible light irradiation," Journal of Photochemistry and Photobiology B, vol. 126, pp. 47-50, 2013.

[152] B. Krishnakumar and M. Swaminathan, "Solar photocatalytic degradation of Naphthol Blue Black," Desalination \& Water Treatment, vol. 51, pp. 6572-6579, 2013.

[153] O. Sharma and M. K. Sharma, "Use of cobalt hexacyanoferrate(II) semiconductor in photocatalytic degradation of neutral red dye," International Journal of ChemTech Research, vol. 5, pp. 1615-1622, 2013.

[154] P. Du, L. Song, J. Xiong, L. Wang, and N. Li, "A photovoltaic smart textile and a photocatalytic functional textile based on co-electronspun $\mathrm{TiO}_{2} / \mathrm{MgO}$ core-sheath nanorods: novel textile of integrating energy and environmental science with textile research," Textile Research Journal, vol. 83, pp. 1690-1702, 2013.

[155] J. Yang, C. Chen, H. Ji, W. Ma, and J. Zhao, "Mechanism of TiO ${ }_{2}$ assisted photocatalytic degradation of dyes under visible irradiation: photoelectrocatalytic study by $\mathrm{TiO}_{2}$-film electrodes," Journal of Physical Chemistry B, vol. 109, no. 46, pp. 21900-21907, 2005.

[156] P. Eskandari, F. Kazemi, and Y. Azizian-Kalandaragh, "Convenient preparation of CdS nanostructures as a highly efficient photocatalyst under blue LED and solar light irradiation," Separation \& Purification Technology, vol. 120, pp. 180-185, 2013.

[157] F. Wen and C. Li, "Hybrid artificial photosynthetic systems comprising semiconductors as light harvesters and biomimetic complexes as molecular cacatalyst," Accounts of Chemical Research, vol. 46, pp. 2355-2364, 2013.

[158] L. M. Duan, J. H. Liu, Q. Y. Pang, L. Xu, and Z. R. Liu, "Efficient sunlight active nanocomposite photocatalytst for degradation of pollutant organic dyes," Advanced Materials Research, vol. 726, pp. 650-653, 2013. 
[159] S. Da Dalt, A. K. Alves, and C. P. Bergmann, "Photocatalytic degradation of methyl orange in water solutions in the presence of MWCNT/TiO ${ }_{2}$ composites," Materials Research Bulletin, vol. 48, pp. 1845-1850, 2013.

[160] N. Divya, A. Bansal, and A. K. Jana, "Photocatalytic degradation of azo Orange II in aqueous solutions using copperimpregnated titania," International Journal of Environmental Science and Technology, vol. 10, pp. 1265-1274, 2013.

[161] J. Dong, H. Xu, F. Zhang, C. Chen, L. Liu, and G. Wu, "Synergistic effect over photocatalytic active $\mathrm{Cu}_{2} \mathrm{O}$ thin films and their morphological and orientational transformation under visible light irradaiation," Applied Catalysis A, vol. 470, pp. 294-302, 2014.

[162] O. Sharma and M. K. Sharma, "Copper hexacyanoferrate (II) as photocatalyst: decolarisation of neutral red dye," International Journal of ChemTech Research, vol. 5, pp. 2706-2716, 2013.

[163] S. S. Shinde, C. H. Bhosale, and K. Y. Rajpure, "Kinetic analysis of heterogenous photocatalysis: role of hydroxyl radicals," Catalysis Review, vol. 55, pp. 79-133, 2013.

[164] K. Zhou, Y. Shi, S. Jiang, Y. Hu, and Z. Gui, "Facile preparation of $\mathrm{Cu}_{2} \mathrm{O} /$ carbon heterostucture with high photocatalytic activity," Materials Letters, pp. 213-216, 2013.

[165] X. Lu, N. Hu, J. Li, H. Ma, K. Du, and R. Zhao, "Influence of TiO impregnated with a novel copper (II) carboxylic porphyrin and its application in photocatalytic degradation of 4-nitrophenol," Research on Chemical Intermediates, vol. 40, no. 5, pp. 1911-1922, 2014.

[166] W. Hu, F. Ren, R. Bai, Z. Zhou, and W. Xu, "Preparation and photocatalytic properties of $\mathrm{CuO}-\mathrm{TiO}_{2}$ /conductive polymer fiber composites," Acta Scientiae Circumstantiae, vol. 33, pp. 431-436, 2013.

[167] P. Deepak and S. Shikha, "Effect of surfactants and electrolyte on removal and recovery of basic dye by using ficus carica cellulosic fibers as biosorbent," Surfactant, vol. 49, pp. 306-314, 2011.

[168] R. O. Cristavoa, A. P. M. Tavares, J. M. Loureiro, R. A. R. Boaventura, and E. A. Macedo, "Optimisation of reactive dye degradation by laccase using Box-Behnken design," Environmental Technology, vol. 29, no. 12, pp. 1357-1364, 2008.

[169] A. Khan, N. A. Mir, M. M. Haque, M. Muneer, and C. Boxall, "Solar photocatalytic decolorization of two azo dye derivatives, acid red 17 and reactive red 241 in aqueous suspension," Science of Advanced Materials, vol. 5, pp. 160-165, 2013.

[170] S. K. Kavitha and P. N. Palanisamy, "Solar photocatalitic degradation of Vat Yellow 4 dye in aqueous suspension of $\mathrm{TiO}_{2}$-optimization of operational parameters," Advances in Environmental Sciences, vol. 2, pp. 189-202, 2010.

[171] S. T. Tan, A. A. Umar, A. Balouch et al., "ZnO nanocubes with (1 $\left.\begin{array}{lll}1 & 0\end{array}\right)$ basal plane photocatalyst prepared via a low-frequency ultrasonic assisted hydrolysis process," Untrasonic Sonochem, vol. 21, pp. 754-760, 2014.

[172] A. A. Taha, A. A. Hriez, Y.-N. Wu, H. Wang, and F. Li, "Direct synthesis of novel vanadium oxide embedded porous carbon nanofiber decorated with iron nanoparticles as a low-cost and highly efficient visible-light-driven photocatalyst," Journal of Colloid and Interface Science, vol. 417, pp. 199-205, 2014.

[173] H. Xu, J. Zhang, Y. Chen, H. Lu, J. Zhuang, and J. Li, "Synthesis of polyaniline-modified $\mathrm{MnO}_{2}$ composite nanorods and their photocatalytic application," Materials Letters, vol. 117, pp. 21-23, 2014.

[174] C. Wang, X. Zhang, B. Yuan et al., "Multi-heterojunction photocatalyst based on $\mathrm{WO}_{3}$ nanorods: structural design and optimization for enchanced photocatalytic activity under visible light," Chemical Engineering Journal, vol. 237, pp. 29-37, 2014.

[175] N. A. S. Al-Areqi, A. Al-Alas, A. S. N. Al-Kamali, K. A. S. Ghaleb, and K. Al-Mureish, "Photodegradation of 4-SPPN dye catalyzed by $\mathrm{Ni}(\mathrm{II})$-substited $\mathrm{Bi}_{2} \mathrm{VO}_{5.5}$ system under visible light irradiation: influence of phase stability and perovskite vanadate oxygen vacancies of photocatalyst," Journal of Molecular Catalysis A, vol. 381, pp. 1-8, 2014.

[176] Y. He, D. Li, J. Chen et al., " $\mathrm{Sn}_{3} \mathrm{O}_{4}$ : a novel heterovalent-tin photocatalyst with hierarchical 3D nanostructures under visible light," RSC Advances, vol. 4, pp. 1266-1269, 2014.

[177] O. F. Lopes, E. C. Paris, and C. Ribeiro, "Synthesis of $\mathrm{Nb}_{2} \mathrm{O}_{5}$ nanoparticles through the oxidant peroxide method applied to organic pollutant photodegradation: a mechanistic study," Applied Catalysis B, vol. 144, pp. 800-808, 2014.

[178] M. Buchalska, J. Kuncewicz, E. Swietek et al., "Photoinduced hole injection in semiconductor-coordination compoun system," Coordination Chemistry Reviews, vol. 257, pp. 767-775, 2013.

[179] A. Abidov, B. Allebergenov, O. Tursunkulov et al., "The evaluation of photocatalytic properties of iron doped titania photocatalyst by degradation of methylene blue using fluorescent light source," Advanced Materials Research, vol. 652, pp. 1700-1703, 2013.

[180] M. Luo, D. Bowden, and P. Brimblecombe, "Removal of dyes from water using a $\mathrm{TiO}_{2}$ photocatalyst supported on black sand," Water, Air, and Soil Pollution, vol. 198, no. 1-4, pp. 233241, 2009.

[181] H. M. Lim, J. S. Jung, D. S. Kim, D. J. Lee, S.-H. Lee, and W. N. Kim, "Modification of natural zeolite powder and its application to interior non-woven textile for indoor air quality control," Materials Science Forum, vol. 510-511, pp. 934-937, 2006.

[182] R. Rahimi, M. M. Moghaddas, S. Zargari, and R. Rahimi, "Synthesis of mesoporous $\mathrm{V}^{-\mathrm{TiO}_{2}}$ with different surfactants: the effect of surfactant type on photocatalytic process," Advanced Materials Research, vol. 702, pp. 56-61, 2013.

[183] L. Pinho, J. C. Hernandez-Garrido, J. J. Calvino, and M. J. Mosquera, "2D and 3D characterization of a surfactantsynthesized $\mathrm{TiO}_{2}-\mathrm{SiO}_{2}$ mesoporous photoctalytst obtained at ambient temperature," Physical Chemistry Chemical Physics, vol. 15, pp. 2800-2808, 2013.

[184] H. Park, Y. Park, W. Kim, and W. Choi, "Surface modification of $\mathrm{TiO}_{2}$ photocatalyst for environmental applications," Journal of Photochemistry and Photobiology C, vol. 15, pp. 1-20, 2013.

[185] P. Goswami, R. K. Debnath, and J. N. Ganguli, "Photophysical and photochemical properties of nanosized cobalt-doped $\mathrm{TiO}_{2}$ photocatalyst," Asian Journal of Chemistry, vol. 25, pp. 71187124, 2013.

[186] H. Meng, B. Wang, S. Liu, R. Jiang, and H. Long, "Hydrothermal preparation, characterization and photocatalytic activity of $\mathrm{TiO}_{2} / \mathrm{Fe}-\mathrm{TiO}_{2}$ composite catalysts," Ceramics International, vol. 39, pp. 5785-5793, 2013.

[187] S. Vivekanandhan, M. Schreiber, C. Mason, A. K. Mohanty, and M. Misra, "Maple leaf (Acer sp.) extract mediated green process for the functionalization of $\mathrm{ZnO}$ powders with silver nanoparticles," Colloids and Surface B, vol. 113, pp. 169-175, 2014.

[188] S. Xie, Y. Liu, Z. Chen, X. Chen, and X. Wang, "Superior photocatalytic properties of phosphorous-doped $\mathrm{ZnO}$ nanocombs," RSC Advances, vol. 3, pp. 26080-26085, 2013.

[189] S. Balachandran, K. Selvam, B. Babu, and M. Swaminathan, "The simple hydrothermal synthesis of $\mathrm{Ag}-\mathrm{ZnO}-\mathrm{SnO}_{2}$ 
nanochain and its multiple applications," Dalton Transactions, vol. 42, pp. 16365-16374, 2013.

[190] J. Miao, Z. Jia, H.-B. Lu, D. Habibi, and L.-C. Zhang, "Heterogenous photocatalytic degradation of mordant black 11 with $\mathrm{ZnO}$ nanoparticles under UV-Vis light," Journal of the Taiwan Institute of Chemical Engineers, 2013.

[191] Q.-L. Ma, R. Xiong, B.-G. Zhai, and Y. M. Huang, "Core-shelled $\mathrm{Zn} / \mathrm{ZnO}$ microspheres synthesised by ultrasonic irradation for photocatalytic applications," Micro \& Nano Letters, vol. 8, pp. 491-495, 2013.

[192] S. Ameen, A. M. Shaheer, H.-K. Seo, and H.-S. Shin, "Mineralization of rhodamine $6 \mathrm{G}$ dye over rose flower-like $\mathrm{ZnO}$ nanomaterials," Materials Letters, vol. 113, pp. 20-24, 2013.

[193] N.-F. Hsu, M. Chang, and K.-T. Hsu, "Rapid synthesis of $\mathrm{ZnO}$ dandelion-like nanostructures and their applications in humidity sensing and photocatalysis," Materials Science in Semiconductor Processing, vol. 21, pp. 200-205, 2014.

[194] N. W. C. Jusoh, A. A. Jalil, S. Triwahyono et al., "Sequential desilication-isomorphous substitution route to prepare mesostructured silica nanoparticles loaded with $\mathrm{ZnO}$ and their photocatalytic activity," Applied Catalysis A, vol. 468, pp. 276287, 2013.

[195] L. M. Duan, J. H. Liu, X. T. Xu, L. Xu, and Z. R. Liu, “The preparation and sunlight activity of nanocomposite photocatalysts for degradation of methyl orange solution," Advanced Materials Research, vol. 750, pp. 1397-1400, 2013.

[196] Y. V. Marathe and V. S. Shrivastava, "Effective removal of non-biodegradable methyl orange dye by using CdS/activated carbon nanocomposite as a photocatalyst," Desalination \& Water Treatment, 2013.

[197] G. Yang, B. Yang, T. Xiao, and Z. Yan, “One-step solvothermal synthesis of hierarchically porous nanostructured $\mathrm{CdS} / \mathrm{TiO}_{2}$ heterojunction with higher visible light photocatalytic activity," Applied Surface Science, vol. 283, pp. 402-410, 2013.

[198] M. Liu, J. Zheng, Q. Liu et al., "The preparation, load and photocatalytic performance of $\mathrm{N}$-doped and CdS-coupled $\mathrm{TiO}_{2}$, , RSC Advabces, vol. 3, pp. 9483-9489, 2013.

[199] J. Fu, B. Chang, Y. Tian, F. Xi, and X. Dong, "Novel $\mathrm{C}_{3} \mathrm{~N}_{4}-\mathrm{CdS}$ composite photocatalysts with organic-inorganic heterojunctions: in situ synthesis, exceptional activity, high stability and photocatalytic mechanism," Journal of Materials Chemistry A, vol. 1, pp. 3083-3090, 2013.

[200] L. Shao, G. Xing, W. Lv et al., "Photodegradation of azo-dyes in aqueous solution by polyacrylonitrile nanofiber mat-supported metalloporphyrins," Polymer International, vol. 62, pp. 289-294, 2013.

[201] N. Sobana, B. Krishnakumar, and M. Swaminathan, "Synergism and effect of operational parameters on solar photocatlytic degradation of an azo dye (Direct Yellow 4) using activated carbon-loaded zinc oxide," Materials Science in Semiconductor Processing, vol. 16, pp. 1046-1051, 2013.

[202] H.-Y. Zhu, J. Yao, R. Jiang, Y.-Q. Fu, Y.-H. Wu, and G.-M. Zeng, "Enchanced decolarization of azo dye solution by cadmium sulfide.multi-walled carbon nanotubes/polymer composite in combination with hydrogen peroxide under simulated solar light irradiation," Ceramics International, vol. 40, pp. 3769-3777, 2014.

[203] N. A. S. Al-Areqi, A. S. N. Al-Kamali, K. A. S. Ghaleb, A. Al_Alas, and K. Al-Mureish, "Influence of phase stabilization and perovskite vanadate oxygen vacancies of the BINIVOX catalyst on photocatalytic degradation of azo dye under visible light irradiation," Radiation Effects \& Defect Solids, vol. 169, pp. 117-128, 2014.

[204] C. Andriantsiferana, E. F. Mohamed, and H. Delmas, "Photocatalytic degradation of an azo-dye on $\mathrm{TiO}_{2}$ /activated carbon composite material," Environmental Technologies, vol. 35, pp. 355-363, 2014.

[205] J. H. Shariffuddin, M. I. Jones, and D. A. Patterson, "Greener photocatalysts: hydroxyapatite derived from waste mussel shells for the photocatalytic degradation of model azo dye wastewater," Chemical Engineering Research and Design, vol. 91, pp. 1693-1704, 2013.

[206] B. Subash, A. Senthilraja, P. Dhatshanamurthi, M. Swaminthan, and M. Shanti, "Solar active photocatalyst for effctive degradation of RR 120 with dye sensitized mechanism," Spectrochimica Acta, vol. 115, pp. 175-182, 2013.

[207] M. H. Habibi and E. Askari, "Spectrophotometric studies of photo-induced degradation of Tertrodirect Light Blue (TLB) using a nanostructure zinc zirconate composite," Journal of Industrial and Engineering Chemistry, vol. 19, pp. 1400-1405, 2013.

[208] H. Liu, G. Li, J. Qu, and H. Liu, "Degradation of azo dye Acid Orange 7 in water by Fe0/granular activated carbon system in the presence of ultrasound," Journal of Hazardous Materials, vol. 144, no. 1-2, pp. 180-186, 2007.

[209] G. Buitrón, M. Quezada, and G. Moreno, "Aerobic degradation of the azo dye acid red 151 in a sequencing batch biofilter," Bioresource Technology, vol. 92, no. 2, pp. 143-149, 2004.

[210] S. M. A. G. Ulson de Souza, E. Forgiarini, and A. A. Ulson de Souza, "Toxicity of textile dyes and their degradation by the enzyme horseradish peroxidase (HRP)," Journal of Hazardous Materials, vol. 147, no. 3, pp. 1073-1078, 2007.

[211] W. Zhai, G. Li, P. Yu, L. Yang, and L. Mao, "Silver phosphate/carbon nanotube-stabilized pickering emulsion for highly efficient photocatalysis," The Journal of Physical Chemistry, vol. 117, pp. 15183-15191, 2013.

[212] K. Ullah, Z.-D. Meng, S. Ye, L. Zhu, and W.-C. Oh, "Synthesis and characterization of novel $\mathrm{PbS}$-graphene/ $\mathrm{TiO}_{2}$ composite with enchanced photocatalytic activity," Journal of Industrial and Engineering Chemistry, vol. 20, no. 3, pp. 1035-1042, 2014.

[213] M. Cheng, M. Zhu, Y. Du, and P. Yang, "Enchanced photocatalytic hydrogen evolution based on efficient electron transfer in triphenylaminebased dye functionalized Au@Pt bimetallic core/shell nanocomposite," International Journal of Hydrogen Energy, vol. 38, pp. 8631-8638, 2013.

[214] T. Soltani and M. H. Entezari, "Photolysis and photocatalysis of methylene blue by ferrite bismuth nanoparticles under sunlight irradiation," Journal of Molecular Catalysis A, vol. 377, pp. 197203, 2013.

[215] H.-Y. Sun, C.-B. Liu, Y. Cong, M.-H. Yu, H.-Y. Bai, and G.B. Che, "New photocatalyst for the degradation of organic dyes based on $\left[\mathrm{Co}_{2}(1,4-\mathrm{BDC})(\mathrm{NCP})_{2}\right]_{\mathrm{n}} \cdot 4 \mathrm{nH}_{2} \mathrm{O}$," Inorganic Chemistry Communications, vol. 35, pp. 130-134, 2013.

[216] R. Comparelli, E. Fanizza, M. L. Curri, P. D. Cozzoli, G. Mascolo, and A. Agostiano, "UV-induced photocatalytic degradation of azo dyes by organic-capped $\mathrm{ZnO}$ nanocrystals immobilized onto substrates," Applied Catalysis B, vol. 60, no. 1-2, pp. 1-11, 2005.

[217] S. K. Sharma, H. Bhunia, and P. K. Bajpai, “ $\mathrm{TiO}_{2}$-assisted photocatlytic degradation of diazo dye reactive red 120: decolarization kinetics and mineralization investigations," Journal of Advanced Oxidation Technologies, vol. 16, pp. 306-313, 2013. 
[218] H. Aliyan, R. Fazaeli, and R. Jalilian, “ $\mathrm{Fe}_{3} \mathrm{O}_{4} @$ mesoporous SBA15: a magnetically recoverable catayst for photodegradation of malachite green," Applied Surface Science, vol. 276, pp. 147-153, 2013.

[219] A. Khanna and V. K. Shetty, "Solar light induced photocatalystic degradation of Reactive Blue 220 (RB 220) dye with highly efficient $\mathrm{Ag} @ \mathrm{TiO}_{2}$ core-shell nanoparticles: a comparision with UV photocatalysis," Solar Energy, vol. 99, pp. 67-76, 2014.

[220] M.-C. Chang, H.-Y. Shu, T.-H. Tseng, and H.-W. Hsu, "Supported zinc oxide photocatalyst for decolarization and mineralization of orange G dye wastewater under UV 365 irradiation," International Journal of Photoenergy, vol. 2013, Article ID 595031, 12 pages, 2013.

[221] K. Zhao, Z. Wu, R. Tang, and Y. Jiang, "Preparation of highly visible-light photocatalytic active N-doped $\mathrm{TiO}_{2}$ microcuboids," Journal of the Korean Chemical Society, vol. 57, pp. 489-492, 2013.

[222] P. Xiong, L. Wang, X. Sun, B. Xu, and X. Wang, "Ternary titania-cobalt ferrite-polyaniline nanocomposite: a magnetically recycleable hybrid for adsorption and photodegradation of dyes under visible light," Industrial \& Engineering Chemistry Research, vol. 52, pp. 10105-10113, 2013.

[223] Y.-J. Xu, Y. Zhuang, and X. Fu, "New insight for enhanced photocatalytic activity of $\mathrm{TiO}_{2}$ by doping carbon nanotubes: a case study on degradation of benzene and methyl orange," Journal of Physical Chemistry C, vol. 114, no. 6, pp. 2669-2676, 2010.

[224] Y. Zhang, J. Wan, and Y. Ke, "A novel approach of preparing $\mathrm{TiO}_{2}$ films at low temperature and its application in photocatalytic degradation of methyl orange," Journal of Hazardous Materials, vol. 177, no. 1-3, pp. 750-754, 2010.

[225] M. R. Xu, G. Ni, and F. Zhao, "Preparation, characterization and photocatalytic properties of $\mathrm{Cu}, \mathrm{P}$-codoped $\mathrm{TiO}_{2}$ nanoparticles," Advanced Materials Research, vol. 239-242, pp. 2562-2565, 2011.

[226] B. Leena, B. Mohit, and K. S. Mohan, "Photocatalysis of giemsa dye: an approach towards biotechnology laboratory effluent treatment," Journal of Environmental \& Analytical Toxicology, vol. 113, pp. 1-10, 2011.

[227] S. G. Abuabara, L. G. C. Rego, and V. S. Batista, "Influence of thermal fluctuations on interfacial electron transfer in functionalized $\mathrm{TiO}_{2}$ semiconductors," Journal of the American Chemical Society, vol. 127, no. 51, pp. 18234-18242, 2005.

[228] I. H. Laura, G. Robert, J. B. Jesse et al., "Spectral characteristics and photosensitization of $\mathrm{TiO}_{2}$ nanoparticles in reverse micelles by perylenes," The Journal of Physical Chemistry B, vol. 117, pp. 4568-4581, 2013.

[229] Y. Zhang, Z.-R. Tang, X. Fu, and Y.-J. Xu, “ $\mathrm{TiO}_{2}$-graphene nanocomposites for gas-phase photocatalytic degradation of volatile aromatic pollutant: is $\mathrm{TiO}_{2}$-graphene truly different from other $\mathrm{TiO}_{2}$-carbon composite materials?" ACS Nano, vol. 4, no. 12, pp. 7303-7314, 2010.

[230] I. Arslan, I. A. Balcioğlu, and D. W. Bahnemann, "Advanced chemical oxidation of reactive dyes in simulated dyehouse effluents by ferrioxalate-Fenton/UV-A and $\mathrm{TiO}_{2} / \mathrm{UV}-\mathrm{A}$ processes," Dyes \& Pigments, vol. 47, no. 3, pp. 207-218, 2000.

[231] I. A. Alaton, I. A. Balcioglu, and D. W. Bahnemann, "Advanced oxidation of a reactive dyebath effluent: comparison of $\mathrm{O}_{3}$, $\mathrm{H}_{2} \mathrm{O}_{2} / \mathrm{UV}-\mathrm{C}$ and $\mathrm{TiO}_{2} / \mathrm{UV}$-A processes," Water Research, vol. 36, no. 5, pp. 1143-1154, 2002.

[232] G. Li, J. Qu, X. Zhang, and J. Ge, "Electrochemically assisted photocatalytic degradation of Acid Orange 7 with $\beta-\mathrm{PbO}_{2}$ electrodes modified by $\mathrm{TiO}_{2}$," Water Research, vol. 40, no. 2, pp. 213-220, 2006.

[233] I. Arslan, I. A. Balcioglu, and D. W. Bahnemann, "Heterogeneous photocatalytic treatment of simulated dyehouse effluents using novel $\mathrm{TiO}_{2}$-photocatalysts," Applied Catalysis B, vol. 26, no. 3, pp. 193-206, 2000.

[234] Z.-X. Lu, L. Zhou, Z.-L. Zhang et al., "Cell damage induced by photocatalysis of $\mathrm{TiO}_{2}$ thin films," Langmuir, vol. 19, no. 21, pp. 8765-8768, 2003.

[235] H. Yu, S. Chen, X. Quan, H. Zhao, and Y. Zhang, "Fabrication of a $\mathrm{TiO}_{2}-\mathrm{BDD}$ heterojunction and its application as a photocatalyst for the simultaneous oxidation of an azo dye and reduction of Cr(VI)," Environmental Science and Technology, vol. 42, no. 10, pp. 3791-3796, 2008.

[236] Z. Zainal, L. K. Hui, M. Z. Hussein, A. H. Abdullah, and I. K. R. Hamadneh, "Characterization of $\mathrm{TiO}_{2}$-Chitosan/Glass photocatalyst for the removal of a monoazo dye via photodegradation-adsorption process," Journal of Hazardous Materials, vol. 164, no. 1, pp. 138-145, 2009.

[237] S. U. M. Khan, M. Al-Shahry, and W. B. Ingler Jr., "Efficient photochemical water splitting by a chemically modified n$\mathrm{TiO}_{2}$," Science, vol. 297, no. 5590, pp. 2243-2245, 2002.

[238] F. Dong, S. Guo, H. Wang, X. Li, and Z. Wu, "Enhancement of the visible light photocatalytic activity of C-doped $\mathrm{TiO}_{2}$ nanomaterials prepared by a green synthetic approach," Journal of Physical Chemistry C, vol. 115, no. 27, pp. 13285-13292, 2011.

[239] P. C. Maness, S. Smolinski, D. M. Blake, Z. Huang, E. J. Wolfrum, and W. A. Jacoby, "Bactericidal activity of photocatalytic $\mathrm{TiO}_{2}$ reaction: toward an understanding of its killing mechanism," Applied and Environmental Microbiology, vol. 65, no. 9, pp. 4094-4098, 2009.

[240] C. Shifu, L. Xuqiang, L. Yunzhang, and C. Gengyu, "The preparation of nitrogen-doped $\mathrm{TiO}_{2-x} \mathrm{~N}_{x}$ photocatalyst coated on hollow glass microbeads," Applied Surface Science, vol. 253, no. 6, pp. 3077-3082, 2007.

[241] D. Chen, D. Yang, Q. Wang, and Z. Jiang, "Effects of boron doping on photocatalytic activity and microstructure of titanium dioxide nanoparticles," Industrial and Engineering Chemistry Research, vol. 45, no. 12, pp. 4110-4116, 2006.

[242] W. Li, Y. Bai, C. Liu et al., "Highly thermal stable and highly crystalline anatase $\mathrm{TiO}_{2}$ for photocatalysis," Environmental Science and Technology, vol. 43, no. 14, pp. 5423-5428, 2009.

[243] D. B. Ingram and S. Linic, "Water splitting on composite plasmonic-metal/semiconductor photoelectrodes: evidence for selective plasmon-induced formation of charge carriers near the semiconductor surface," Journal of the American Chemical Society, vol. 133, no. 14, pp. 5202-5205, 2011.

[244] J.-H. Sun, S.-Y. Dong, Y.-K. Wang, and S.-P. Sun, "Preparation and photocatalytic property of a novel dumbbell-shaped $\mathrm{ZnO}$ microcrystal photocatalyst," Journal of Hazardous Materials, vol. 172, no. 2-3, pp. 1520-1526, 2009.

[245] W. Xie, Y. Li, W. Sun, J. Huang, H. Xie, and X. Zhao, "Surface modification of $\mathrm{ZnO}$ with $\mathrm{Ag}$ improves its photocatalytic efficiency and photostability," Journal of Photochemistry and Photobiology A, vol. 216, no. 2-4, pp. 149-155, 2010.

[246] W. Chen, W. Lu, Y. Yao, and M. Xu, "Highly efficient decomposition of organic dyes by aqueous-fiber phase transfer and in situ catalytic oxidation using fiber-supported cobalt phthalocyanine," Environmental Science and Technology, vol. 41, no. 17, pp. 6240-6245, 2007.

[247] A. C. Lucilha, C. E. Bonancêa, W. J. Barreto, and K. Takashima, "Adsorption of the diazo dye Direct Red 23 onto a zinc oxide 
surface: a spectroscopic study," Spectrochimica Acta Part A, vol. 75, no. 1, pp. 389-393, 2010.

[248] L. S. Andrade, L. A. M. Ruotolo, R. C. Rocha-Filho et al., "On the performance of $\mathrm{Fe}$ and $\mathrm{Fe}, \mathrm{F}$ doped $\mathrm{Ti}-\mathrm{Pt} / \mathrm{PbO}_{2}$ electrodes in the electrooxidation of the Blue Reactive 19 dye in simulated textile wastewater," Chemosphere, vol. 66, no. 11, pp. 2035-2043, 2007.

[249] M. Nasr-Esfahani and M. H. Habibi, "Silver doped $\mathrm{TiO}_{2}$ nanostructure composite photocatalyst film synthesized by solgel spin and dip coating technique on glass," International Journal of Photoenergy, vol. 2008, Article ID 628713, 11 pages, 2008.

[250] L. Björnsson, P. Hugenholtz, G. W. Tyson, and L. L. Blackall, "Filamentous Chloroflexi (green non-sulfur bacteria) are abundant in wastewater treatment processes with biological nutrient removal," Microbiology, vol. 148, no. 8, pp. 2309-2318, 2002.

[251] J. J. Plumb, J. Bell, and D. C. Stuckey, "Microbial populations associated with treatment of an industrial dye effluent in an anaerobic baffled reactor," Applied and Environmental Microbiology, vol. 67, no. 7, pp. 3226-3235, 2001.

[252] T. Ito, K. Sugita, and S. Okabe, "Isolation, characterization, and in situ detection of a novel chemolithoautotrophic sulfuroxidizing bacterium in wastewater biofilms growing under microaerophilic conditions," Applied and Environmental Microbiology, vol. 70, no. 5, pp. 3122-3129, 2004.

[253] S. M. Burkinshaw and G. W. Collins, "Aftertreatment to reduce the washdown of leuco sulphur dyes on cotton during repeated washing," Journal of the Society of Dyers and Colourists, vol. 114, no. 5-6, pp. 165-168, 1998.

[254] R. S. Shraddha, S. Simran, K. Mohit, and K. Ajay, "Laccase: microbial sources, production, purification, and potential biotechnological applications," Enzyme Research, vol. 2011, Article ID 217861, 11 pages, 2011.

[255] M. Alvaro, E. Carbonell, M. Esplá, and H. Garcia, "Iron phthalocyanine supported on silica or encapsulated inside zeolite $\mathrm{Y}$ as solid photocatalysts for the degradation of phenols and sulfur heterocycles," Applied Catalysis B, vol. 57, no. 1, pp. 37-42, 2005.

[256] S.-L. Chen, X.-J. Huang, and Z.-K. Xu, "Functionalization of cellulose nanofiber mats with phthalocyanine for decoloration of reactive dye wastewater," Cellulose, vol. 18, no. 5, pp. 12951303, 2011.

[257] K. K. Kim, C. S. Lee, R. M. Kroppenstedt, E. Stackebrandt, and S. T. Lee, "Gordonia sihwensis sp. nov., a novel nitrate-reducing bacterium isolated from a wastewater-treatment bioreactor," International Journal of Systematic and Evolutionary Microbiology, vol. 53, no. 5, pp. 1427-1433, 2003.

[258] L. Zhou, W. Guo, G. Xie, and J. Feng, "Photocatalytic degradation of reactive brilliant red $\mathrm{X}-3 \mathrm{~B}$ over $\mathrm{BiOI}$ under visible light irradiation," Desalination \& Water Treatment, vol. 51, pp. 65176525, 2013.

[259] D. C. Xu, Z.-W. Lian, M.-L. Fu, B. Yuan, J.-W. Shi, and H.-J. Cui, "Advanced near-infrared-driven photocatalyst: fabrication, characterization and photocatalytic performance of $\beta-\mathrm{NaYF}_{4}$ : $\mathrm{Yb}^{3+}, \mathrm{Tm}^{3+} @ \mathrm{TiO}_{2}$ core@ shell microcrystals," Applied Catalysis B, vol. 142, pp. 377-386, 2013.

[260] S. Song, L. Xu, Z. He, J. Chen, X. Xiao, and B. Yan, "Mechanism of the photocatalytic degradation of C.I. reactive black 5 at $\mathrm{pH}$ 12.0 using $\mathrm{SrTiO}_{3} / \mathrm{CeO}_{2}$ as the catalyst," Environmental Science and Technology, vol. 41, no. 16, pp. 5846-5853, 2007.

[261] C. Pan and Y. Zhu, "New type of $\mathrm{BiPO}_{4}$ Oxy-acid salt photocatalyst with high photocatalytic activity on degradation of dye,"
Environmental Science and Technology, vol. 44, no. 14, pp. 55705574,2010

[262] A. Furube, T. Shiozawa, A. Ishikawa, A. Wada, K. Domen, and C. Hirose, "Femtosecond transient absorption spectroscopy on photocatalysts: $\mathrm{K}_{4} \mathrm{Nb}_{6} \mathrm{O}_{17}$ and $\mathrm{Ru}(\mathrm{bpy})_{3}{ }^{2+}$-intercalated $\mathrm{K}_{4} \mathrm{Nb}_{6} \mathrm{O}_{17}$ thin films," Journal of Physical Chemistry B, vol. 106, no. 12, pp. 3065-3072, 2002.

[263] U. Ruh, S. Hongqi, W. Shaobin, M. A. Hua, and O. T. Moses, "Wet-chemical synthesis of $\mathrm{InTaO}_{4}$ for photocatalytic decomposition of organic contaminants in air and water with UV-vis light," Industrial \& Engineering Chemistry Research, vol. 51, pp. 1563-1569, 2011.

[264] V. Gunasekar, B. Divya, K. Brinda, J. Vijakrishnan, V. Ponnusami, and K. S. Rajan, "Enzyme mediated synthesis of Ag$\mathrm{TiO}_{2}$ photocatalyst for visible light degradation of reactive dye from aqueous solution," Journal of Sol-Gel Science and Technology, vol. 68, pp. 60-66, 2013.

[265] X. Liu, J. Xing, J. Qiu, and X. Sun, "Preparation and characterization of visible light-driven praseodymium-doped mesoporous titania coated magnetite photocatalyst," Indian Journal of Chemistry, vol. 52, pp. 1257-1262, 2013.

[266] Y. Y. Wang, H. Xie, W. Zhang, Y. B. Tang, and F. Y. Chen, "Preparation and photocatalytic activity of Fe-Ce-N tri-doped $\mathrm{TiO}_{2}$ photocatalyst," Advanced Materials Research, vol. 750, pp. 1276-1282, 2013.

[267] L. Liu, H. Bai, J. Liu, and D. D. Sun, "Multifuntional graphene oxide- $\mathrm{TiO}_{2}-\mathrm{Ag}$ nanocomposites for high performance water disinfection and decontamination under solar irradiation," Journal of Hazardous Materials, vol. 261, pp. 214-223, 2013.

[268] C. T. Nam, W.-D. Yang, and L. M. Duc, "Study on photocatalysis of $\mathrm{TiO}_{2}$ nanotubes prepared by methanol-thermal synthesis at low temperature," Bulletin of Materials Science, vol. 36, pp. 779778, 2013.

[269] X. Lin, D. Fu, L. Hao, and Z. Ding, "Synthesis and enchanced visible-light responsive of $\mathrm{C}, \mathrm{N}$, S-tridoped $\mathrm{TiO}_{2}$ hollow spheres," Journal of Environmental Sciences, vol. 25, pp. 21502156, 2013.

[270] L.-X. Zhu, Z.-H. Zhao, X.-Y. Yue, and J.-M. Fan, "One-pot hydrothermal synthesis of $\mathrm{Ag} @ \mathrm{Ag} 2 \mathrm{~S}$ modified porous $\mathrm{TiO}_{2}$ and its photocatalytic and antimicrobial properties," Journal of Molecular Catalysis, vol. 27, pp. 467-473, 2013.

[271] C. Namasivayam, R. Jeyakumar, and R. T. Yamuna, "Dye removal from wastewater by adsorption on "waste" $\mathrm{Fe}(\mathrm{III}) / \mathrm{Cr}$ (III) hydroxide," Waste Management, vol. 14, no. 7, pp. 643-648, 1994.

[272] A. Jain, K. P. Raven, and R. H. Loeppert, "Arsenite and arsenate adsorption on ferrihydrite: surface charge reduction and net OH-release stoichiometry," Environmental Science and Technology, vol. 33, no. 8, pp. 1179-1184, 1999.

[273] A. Gürses, M. Yalçin, and C. Doğar, "Electrocoagulation of some reactive dyes: a statistical investigation of some electrochemical variables," Waste Management, vol. 22, no. 5, pp. 491499, 2002.

[274] H. Lachheb, E. Puzenat, A. Houas et al., "Photocatalytic degradation of various types of dyes (Alizarin S, Crocein Orange G, Methyl Red, Congo Red, Methylene Blue) in water by UVirradiated titania," Applied Catalysis B, vol. 39, no. 1, pp. 75-90, 2002.

[275] C. Guillard, H. Lachheb, A. Houas, M. Ksibi, E. Elaloui, and J.-M. Herrmann, "Influence of chemical structure of dyes, of $\mathrm{pH}$ and of inorganic salts on their photocatalytic degradation 
by $\mathrm{TiO}_{2}$ comparison of the efficiency of powder and supported $\mathrm{TiO}_{2}$," Journal of Photochemistry and Photobiology A, vol. 158, no. 1, pp. 27-36, 2003.

[276] F. Han, V. S. R. Kambala, M. Srinivasan, D. Rajarathnam, and R. Naidu, "Tailored titanium dioxide photocatalysts for the degradation of organic dyes in wastewater treatment: a review," Applied Catalysis A, vol. 359, no. 1-2, pp. 25-40, 2009.

[277] C.-Y. Kuo, "Prevenient dye-degradation mechanisms using $\mathrm{UV} / \mathrm{TiO}_{2} /$ carbon nanotubes process," Journal of Hazardous Materials, vol. 163, no. 1, pp. 239-244, 2009.

[278] M. Alvaro, E. Carbonell, and H. Garcia, "Photocatalytic degradation of sulphur-containing aromatic compounds in the presence of zeolite-bound 2,4,6-triphenylpyrylium and 2,4,6triphenylthiapyrylium," Applied Catalysis B, vol. 51, no. 3, pp. 195-202, 2004.

[279] M. Alvaro, E. Carbonell, H. Garcia, C. Lamaza, and M. Narayana Pillai, "Ship-in-a-bottle synthesis of 2,4,6triphenylthiapyrylium cations encapsulated in zeolites $\mathrm{Y}$ and beta: a novel robust photocatalyst," Photochemical and Photobiological Sciences, vol. 3, no. 2, pp. 189-193, 2004.

[280] H.-Y. Xu, W.-C. Liu, J. Shi, H. Zhao, and S.-Y. Qi, "Photocatalytic discoloration of Methyl Orange by anatase/schorl composite: optimization using response surface method," Environmental Science and Pollution Research, vol. 21, no. 2, pp. 1582-1591, 2014.

[281] J. Cao, C. Zhou, H. Lin, B. Xu, and S. Chen, "Direct hydroysis preparation of plate-like $\mathrm{BiOI}$ and their visible light photocatalytic activity for contaminant removal," Materials Letters, vol. 109, pp. 74-77, 2013.

[282] S. Sharma, R. Ameta, R. K. Malkani, and S. C. Ameta, "Use of semi-conducting bismuth sulfide as a photocatalyst for degradation of Rose Bengal," Macedonian Journal of Chemistry and Chemical Engineering, vol. 30, no. 2, pp. 229-234, 2011.

[283] Q. Yan, J. Wang, X. Han, and Z. Liu, "Soft-chemical method for fabrication of $\mathrm{SnO}-\mathrm{TiO}_{2}$ nanocomposites with enchanced photocatalytic activity," Journal of Materials Research, vol. 28, pp. 1862-1869, 2013.

[284] J. Liu, Q. Yang, W. Yang, M. Li, and Y. Song, "Aquatic plant inspired hierarchical artificial leaves for highly efficient photocatalysis," Journal of Materials Chemistry A, vol. 26, pp. 77607766, 2013.

[285] A. Y. Stepanov, L. V. Sotnikova, A. A. Vladimirov, D. V. Dyagilev, and T. A. Larichev, "The synthesis and investigation of crystallographic and adsorption properties of $\mathrm{TiO}_{2}$ powders," Advanced Materials Research, vol. 704, pp. 92-97, 2013.

[286] S. Moradi, P. Aberoomand-Azar, S. Raeis-Farshid, S. AbediniKhorrami, and M. H. Givianrad, "Synthesis and characterzation of $\mathrm{Al}-\mathrm{TiO}_{2} / \mathrm{ZnO}$ and $\mathrm{Fe}-\mathrm{TiO}_{2} / \mathrm{ZnO}$ photocatalyst and their photocatalytic behaviour," Asian Journal of Chemistry, vol. 25, pp. 6635-6638, 2013.

[287] W.-J. Yoo and S. Kobayashi, "Hydrophosphinylation of unactivated alkenes with secondary phosphine oxides under visiblelight photocatalysis," Green Chemistry, vol. 15, pp. 1844-1848, 2013.

[288] Y. Zhang, Y. Zhang, and J. Tan, "Novel magnetically separable $\mathrm{AgCl} /$ iron oxide composites with enchanced photocatalytic activity driven by visible light," Journal of Alloys and Compounds, vol. 574, pp. 383-390, 2013.

[289] H.-N. Cui, J.-Y. Wang, M.-Q. Hu et al., "Efficient photo-driven hydrogen evolution by binuclear nickle catalysts of different coordination in noble-metal-free systems," Dalton Transactions, vol. 42, pp. 8684-8691, 2013.
[290] Q. Zhang, C. Tian, A. Wu, Y. Hong, M. Li, and H. Fu, "In situ oxidation of $\mathrm{Ag} / \mathrm{ZnO}$ by bromine water to prepare ternary Ag-AgBr/ZnO sunlight-derived photocatalyst," Journal of Alloys and Compounds, vol. 563, pp. 269-273, 2013.

[291] L. Li, X. Liu, Y. Zhang et al., "Visible-light photochemical activity of heterostructured core-shell materials composed of selected ternary titanates and ferrites coated by $\mathrm{TiO}_{2}$," ACS Applied Materials \& Interfaces, vol. 5, pp. 5064-5071, 2013.

[292] P. Jiang, D. Ren, D. He, W. Fu, J. Wang, and M. Gu, "An easily sedimentable and effective $\mathrm{TiO}_{2}$ photocatalyst for removal of dyes in water," Separation \& Purification Technology, vol. 122, pp. 128-132, 2014.

[293] P. Guo, L. T. Meng, and C. H. Wang, "Core-shell $\mathrm{WO}_{3} / \mathrm{TiO}_{2}$ nanorod heterostructures for solar light photocatalysis," Advanced Materials Research, vol. 850, pp. 78-81, 2014.

[294] K. Ullah, S. Ye, L. Zhu, Z.-D. Meng, S. Sarkar, and W.-C. Oh, "Microwave assisted synthesis of a noble metal-graphene hybrid photocatalyst for high efficient decomposition of organic dyes under visible light," Materials Science and Engineering B, vol. 180, pp. 20-26, 2014.

[295] R. Adhikari, G. Gyawali, S. H. Cho, R. Narro-Garcia, T. Sekino, and S. W. Lee, " $\mathrm{Fe}^{3+} / \mathrm{Yb}^{3+}$ co-doped bismuth molybdote nanosheets upconversion photocatalyst with enchanced photocatalytic activity," Journal of Solid State Chemistry, vol. 209, pp. 74-81, 2014.

[296] J. Gamage McEvoy, W. Cui, and Z. Zhang, "Synthesis and characterization of $\mathrm{Ag} / \mathrm{AgCl}$-activated carbon composites for enchanced visible light photocatalysis," Applied Catalysis B, vol. 144, pp. 702-712, 2014.

[297] M. Shamshi Hassan, T. Amma, and M.-S. Khil, "Synthesis of high aspect ratio $\mathrm{CdTiO}_{3}$ nanofibers via electrospinning: characterization and photocatalytic activity," Ceramics International, vol. 40, pp. 423-427, 2014.

[298] C. Karakaya, Y. Türker, and O. Dag, "Molten-salt-assisted self-assembly (MASA)-synthesis of mesoporous metal titanatetitania, metal sulfide-titania, and metal selenide-titania thin films," Advanced Functional Materials, vol. 23, pp. 4002-4010, 2013.

[299] X. Cai, Y. Cai, Y. Liu et al., "Photocatalytic degradation properties of $\mathrm{Ni}(\mathrm{OH})_{2}$ nanosheets/ $\mathrm{ZnO}$ nanorods composites for azo dyes under visible-light irradaiation," Ceramics International, vol. 40, pp. 57-65, 2014.

[300] X. Zhang, W. Chen, Z. Lin, and J. Yao, "Preparation and photocatalysis performances of bacterial cellulose $/ \mathrm{TiO}_{2}$ composite membranes doped by rare earth elements," Chinese Journal of Materials Research, vol. 24, no. 5, pp. 540-546, 2010.

[301] X. Zhang, W. Chen, Z. Lin, J. Yao, and S. Tan, "Preparation and photocatalysis properties of bacterial cellulose $/ \mathrm{TiO}_{2}$ composite membrane doped with rare earth elements," Synthesis and Reactivity in Inorganic, Metal-Organic and Nano-Metal Chemistry, vol. 41, no. 8, pp. 997-1004, 2011.

[302] G. Manimegalai, S. Shantha Kumar, and C. Sharma, "Pesticide mineralization in water using silver nanoparticles," International Journal of Chemical Sciences, vol. 9, no. 3, pp. 1463-1471, 2011.

[303] A. Yahia Cherif, O. Arous, M. Amara, S. Omeiri, H. Kerdjoudj, and M. Trari, "Synthesis of modified polymer inclusion membranes for photo-electrodeposition of cadmium using polarized electrodes," Journal of Hazardous Materials, vol. 227, pp. 386393, 2012.

[304] J. Taranto, D. Frochot, and P. Pichat, "Photocatalytic air purification: comparative efficacy and pressure drop of a $\mathrm{TiO}_{2}$-coated 
thin mesh and a honeycomb monolith at high air velocities using a $0.4 \mathrm{~m} 3$ close-loop reactor," Separation \& Purification Technology, vol. 67, no. 2, pp. 187-193, 2009.

[305] A. R. Khataee and M. B. Kasiri, "Photocatalytic degradation of organic dyes in the presence of nanostructured titanium dioxide: influence of the chemical structure of dyes," Journal of Molecular Catalysis A, vol. 328, no. 1-2, pp. 8-26, 2010. 

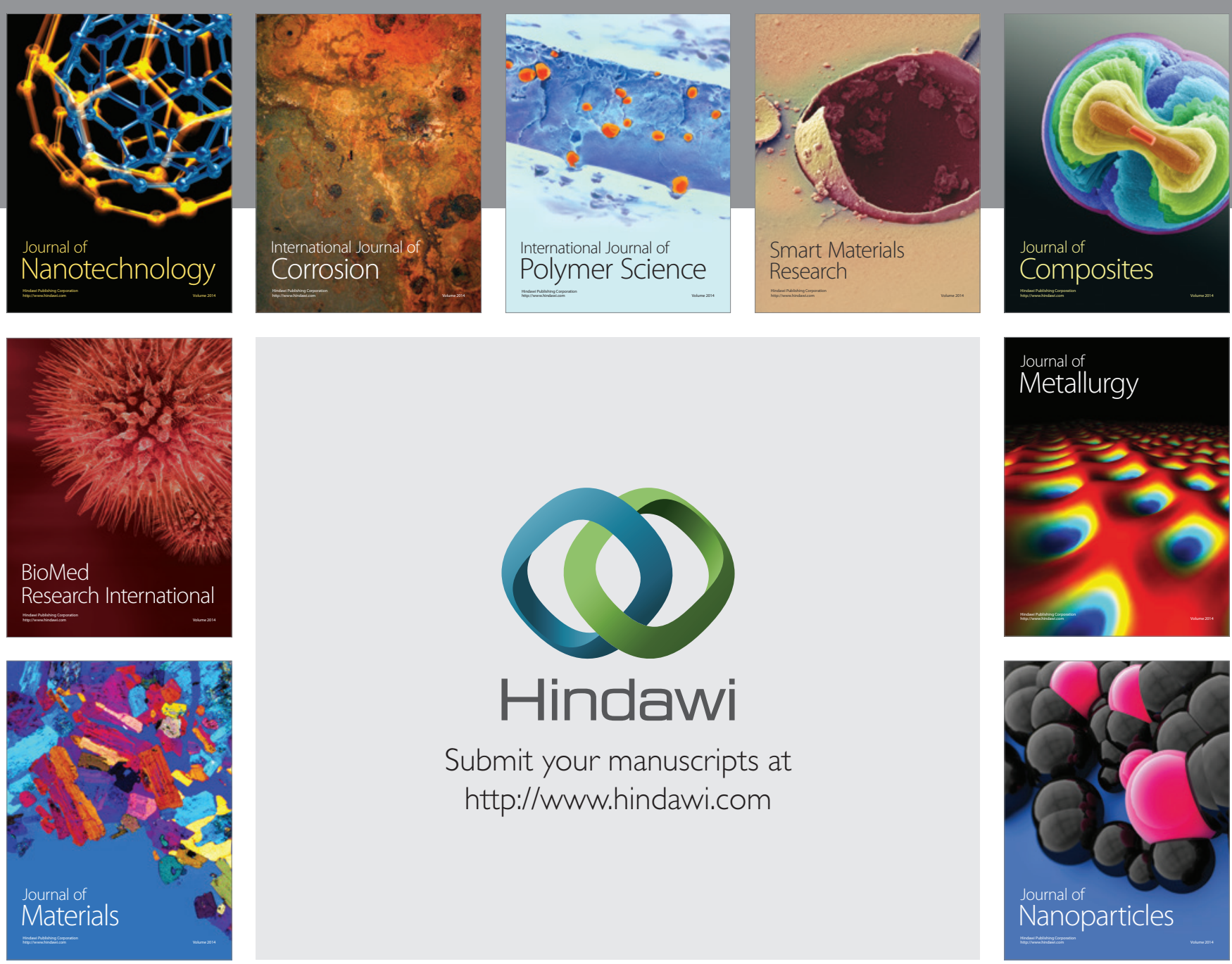

Submit your manuscripts at http://www.hindawi.com
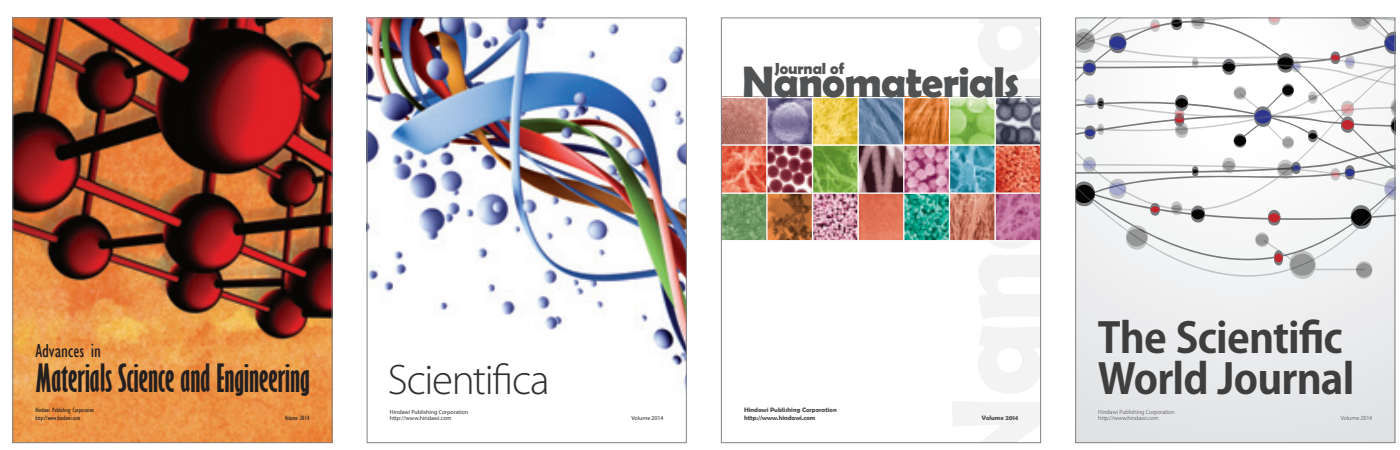

\section{The Scientific World Journal}
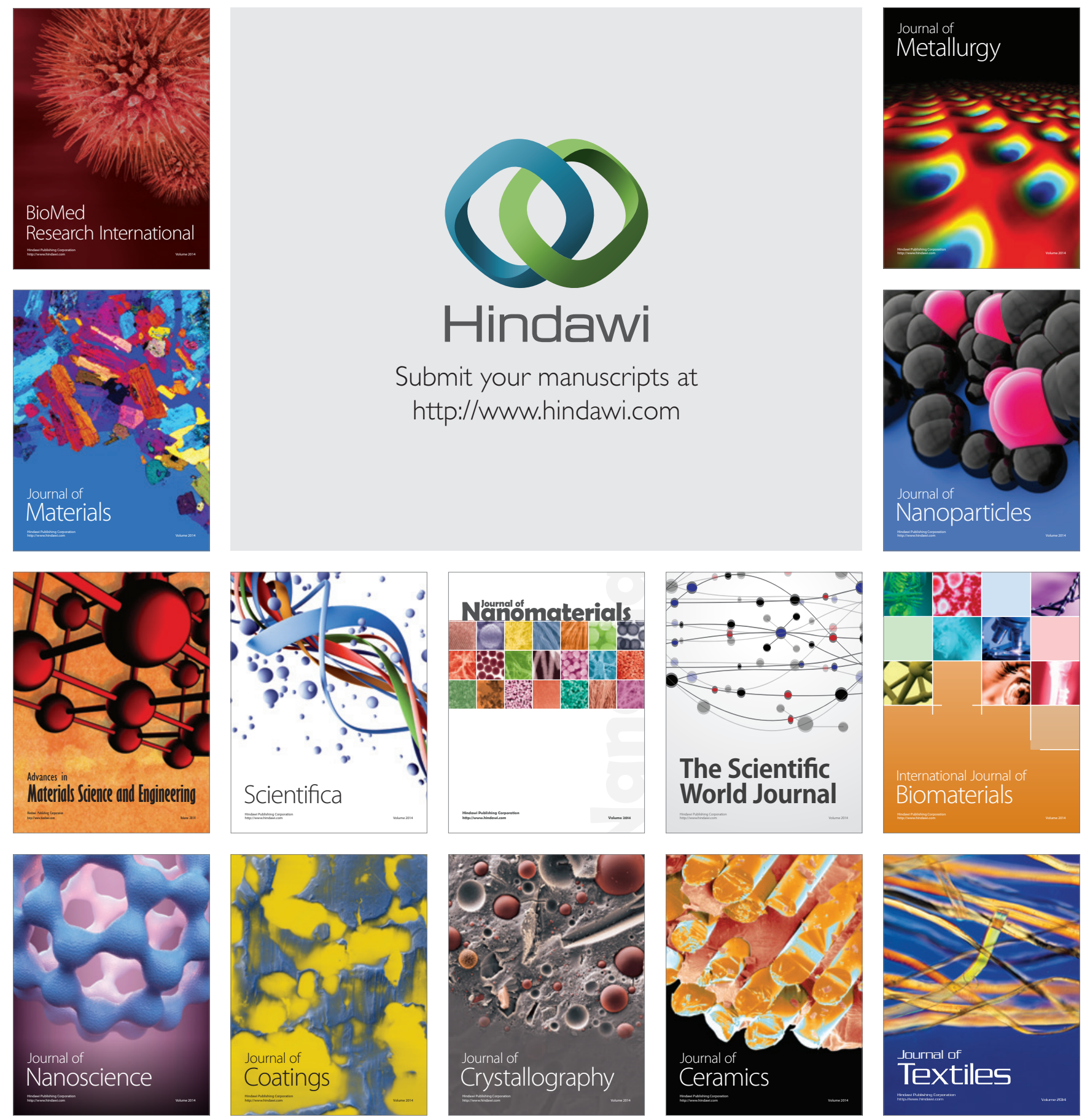